\title{
Ergonomics
}

\section{Variability in decision-making and critical cue use by different road users at rail level crossings}

\section{Vanessa Beanland, Michael G. Lenné, Paul M. Salmon \& Neville A. Stanton}

To cite this article: Vanessa Beanland, Michael G. Lenné, Paul M. Salmon \& Neville A. Stanton (2015): Variability in decision-making and critical cue use by different road users at rail level crossings, Ergonomics, DOI: 10.1080/00140139.2015.1095356

To link to this article: http://dx.doi.org/10.1080/00140139.2015.1095356

View supplementary material $\asymp$

Accepted online: 22 Sep 2015.

Submit your article to this journal $₫$

Q View related articles $₫$

View Crossmark data $\nearrow$ 
Publisher: Taylor \& Francis

Journal: Ergonomics

DOI: http://dx.doi.org/10.1080/00140139.2015.1095356

\section{Variability in decision-making and critical cue use by different road users at rail level crossings}

Vanessa Beanland $^{\text {a,b }}$, Michael G. Lenné ${ }^{\mathrm{b}}$, Paul M. Salmon ${ }^{\mathrm{c}, \mathrm{b}}$, and Neville A. Stanton ${ }^{\text {d }}$

${ }^{a}$ Research School of Psychology, The Australian National University, Canberra, ACT 2601, Australia; ${ }^{b}$ Monash University Accident Research Centre, Monash University, Clayton, VIC 3800, Australia; ${ }^{c}$ Centre for Human Factors and Sociotechnical Systems, University of the Sunshine Coast, Maroochydore, QLD 4558, Australia; ${ }^{d}$

Transportation Research Group, University of Southampton, Southampton, UK

Corresponding author. Email: vanessa.beanland@anu.edu.au 


\section{Variability in decision-making and critical cue use by different road users at rail level crossings}

Collisions at rail level crossings (RLXs) are typically high-severity and high-cost, often involving serious injuries, fatalities and major disruptions to the transport network. Most research examining behaviour at RLXs has focused exclusively on drivers and consequently there is little knowledge on how other road users make decisions at RLXs. We collected drivers', motorcyclists', bicyclists' and pedestrians' self-reported daily experiences at RLXs for two weeks, focusing on behaviour, decision-making and information use in the presence of a train and/or activated RLX signals. Both information use and behaviour differed between road users. Visual information (e.g., flashing lights) was more influential for motorists, whereas pedestrians and cyclists relied more on auditory information (e.g., bells). Pedestrians were also more likely to violate active RLX warnings and/or cross before an approaching train. These results emphasise the importance of adopting holistic RLX design approaches that support cognition and behaviour across for all road users.

Keywords: rail level crossings; grade crossings; decision-making; situation awareness

Practitioner summary: This study explores how information use and decisionmaking at rail level crossings (RLXs) differs between road user groups, using a two-week self-report study. Most users make safe decisions, but pedestrians are most likely to violate RLX warnings. Information use (visual vs. auditory) also differs substantially between road user groups.

\section{Introduction}

Rail level crossings (RLXs; also called highway-rail grade crossings) are complex sociotechnical systems in which human (e.g., vehicle operators, pedestrians) and nonhuman (e.g., boom gates, flashing lights, trains, road vehicles) agents interact. RLX systems encompass diverse agents including train drivers, rail infrastructure, signals, signal operators, vehicle drivers, pedestrians, cyclists and motorcyclists (Read, Salmon, 
and Lenné 2013). Characteristics of RLX systems can be similarly diverse: train lines may intersect with a road, path or both; and infrastructure may include active or passive warnings (see Fig. $1 \&$ 2). Active RLX warnings include flashing lights, audible bells, boom barriers and automatic gates that activate when a train is approaching. Passive $R L X$ warnings are static signs that simply signal the presence of an RLX. In Australia nearly two-thirds of the 9,400 public RLXs have only passive warnings (ATSB 2008), with active infrastructure most common in metropolitan areas.

[FIG 1 \& 2 HERE]

Collisions at RLXs comprise a small percentage of road crashes but are a priority due to their disproportionate impact (Wigglesworth 1976): they have high percrash casualty rates; can substantially disrupt rail and road networks; and impose enormous financial burden. Recent estimates suggest Australian RLX crashes cost A \$116,000,000 annually (Tooth and Balmford 2010) but costs fluctuate because a single, severe collision can cost over A $\$ 30,000,000$ (ATSB 2008). The devastating impact of RLX crashes was highlighted in June 2007 when a semi-trailer truck collided with a passenger train near Kerang, Victoria, Australia, killing 11 train passengers. Investigation revealed the truck driver failed to detect the train, despite several passive and active warnings (for analysis, see Salmon, Read, et al. 2013). This has prompted research examining the functioning of RLX systems and warnings, to understand why some warnings are ineffective and how they might be improved.

Reducing collisions requires understanding factors involved in not only collisions, but also user behaviour more broadly. Human factors are a major contributor to RLX collisions (Caird et al. 2002; Edquist et al. 2009), yet our understanding of influences on behaviour at RLXs remains poor. Previous research has relied on methods that provide limited insight into cognitive processes; for example, roadside observations 
of signal compliance (e.g., Lobb, Harre, and Terry 2003; Tey, Ferreira, and Wallace 2011). Observation provides essential data on how road users behave at RLXs but in order to realise its full value this data must be supplemented by methods that offer insight into why individuals exhibit these behaviours. This includes gaining insight into road users' anticipatory schemata, or mental models of what they expect to encounter (Neisser 1976; Plant and Stanton 2013a). Schemata are formed through experience and direct subsequent exploration and interpretation of our environment, meaning that information-seeking (and, consequently, decision-making based on that information) will be jointly determined by the RLX environment and our schema. Neisser (1976) argued that schemata have greatest influence in ambiguous situations, such situations in which it is unclear whether it is safe to cross an RLX. Thus understanding elements of schemata, such critical cues and influencing factors, could be beneficial for predicting how users will respond to different situations and systems.

A further limitation is that RLX research has focused predominantly on car drivers (Edquist et al. 2009), despite the fact that interactions between agents, rather than behaviours of isolated agents, are of greatest value in understanding RLX collisions (Salmon, Read, et al. 2013). Recently in road safety there has been a shift from individual driver-centred views, which emphasise human error as the leading cause of road crashes, to systems approaches that view both safety and accidents as emerging from interactions between agents (Larsson, Dekker, and Tingvall 2010). Unfortunately, this shift has not yet been mirrored in RLX safety research (Read, Salmon, and Lenné 2013). Empirical research is needed to explore how different users interact with RLX systems, to assess whether existing designs appropriately accommodate all users' decision-making strategies. This represents a first step towards implementing a systems approach to RLX design and safety, identifying how diverse 
agents interact with system infrastructure. Subsequent research can use these insights to more fully adopt a systems approach, by studying overall system functioning.

The notion that different agents experience a system in divergent ways is not unique to RLXs. Situation awareness, our understanding of what is happening around us (Endsley 1995), varies between transport modalities because users differ in their goals, tasks, and system interactions (Cornelissen et al. 2013; Cornelissen, Salmon, and Young 2012; Salmon, Young, and Cornelissen 2013; Salmon, Lenné, Walker, et al. 2014; Walker, Stanton, and Salmon 2011). Within multi-user systems, situation awareness can be overlapping, whereby different agents possess the same information, or distributed, whereby different agents possess distinct but complementary information (Stanton et al. 2006). Distributed situation awareness provides compensatory processes, in that if one agent lacks specific information they may derive it from another agent. Within the RLX context, situation awareness may be distributed across traffic signals (e.g., inactive signals convey there is no train coming, so drivers do not visually confirm this; see Lenné, Beanland, et al. 2013; Lenné, Salmon, et al. 2013; Young et al. 2014), or other road users (e.g., if one vehicle stops, this could cue other nearby vehicles to stop even if they have not directly observed the train; see Salmon, Lenné, Beanland, et al. 2014; Young et al. 2015).

Even when users attend to identical information, it will be combined in distinct ways (Stanton et al. 2009a, 2009b; Stanton et al. 2010). These differences can give rise to "cognitive incompatibilities" when road users have conflicting goals or fail to consider each other (Walker, Stanton, and Salmon 2011) and these incompatibilities are particularly pronounced at intersections (Salmon, Lenné, Walker, et al. 2014). Physical limitations and vulnerabilities shape road users' interactions with each other and the road system, and infrastructure design can either facilitate or prevent conflicts between 
road users (Salmon, Young, and Cornelissen 2013). Consequently it is reasonable to assume that the RLX environment will give rise to varying experiences and support some road users better than others.

\section{Research Aims}

The current study aimed to explore the extent to which: (i) road user groups differ in behaviour at RLXs; (ii) existing RLX designs support different users; and (iii) existing users support each other (e.g., via distributed situation awareness). These issues were examined using a prospective longitudinal study of self-reported experiences at RLXs, focusing on factors that influence decision-making (e.g., critical cues, information use) and differences between road users, comparing drivers, motorcyclists, cyclists and pedestrians.

\section{Method}

\subsection{Participants}

The sample comprised 166 adult residents of Victoria, Australia (pop. 5.4 million); Table 1 provides sample demographics. Participants were required to cross RLXs multiple times a week as a driver, motorcyclist, cyclist or pedestrian. Multimodal transport users were asked to nominate which mode they used most frequently at RLXs. These criteria ensured all participants had experience crossing RLXs in their nominated mode and were likely to encounter RLXs during the study. Most respondents (80\%) lived in metropolitan Melbourne (pop. 4 million), with 20\% from rural Victoria. All participants provided informed consent and were offered AUD\$30. Ethical aspects of the research were approved by Monash University Human Research Ethics Committee.

[TABLE 1 HERE] 


\subsection{Materials}

Initially participants provided demographic information including age, sex, location, years of licensure (drivers and motorcyclists), frequency of mode use (hours/week) and RLX exposure. Participants then completed daily exposure questionnaires for two weeks, reporting transportation use, number and type(s) of RLXs crossed and whether they encountered any trains and/or activated warnings. This section required 2-3 minutes to complete.

On days when the participant encountered a train and/or activated warnings, they were prompted to describe this encounter in detail through structured responses to a series of questions modelled on Critical Decision Method (CDM; Klein, Calderwood, and MacGregor 1989) cognitive task analysis, designed to aid recall of past events. This section required 10-15 minutes to complete.

CDM has been applied to model naturalistic decision-making in workplace accidents (Salmon et al. 2011), aviation (Plant and Stanton 2013b), patient treatment (Galanter and Patel 2005) and other critical situations (Hoffman, Crandall, and Shadbolt 1998; O’Hare et al. 1998). Although CDM is typically administered via individual interviews with small, specialised samples, recent research has adapted the CDM approach in larger survey samples. In one study, driver training participants provided written responses to CDM probes, with a researcher on hand to provide guidance or clarification. This procedure elicited rich descriptions of decision-making and situation awareness during a preceding 45-minute test drive (Walker et al. 2009).

We used two formats for our CDM survey: online and paper. Both formats provided similar support (participants could contact a researcher for assistance) but the online mode provided additional flexibility; questions were displayed sequentially and according to set criteria, with follow-up questions based on responses. In the paper format, prompts were provided sequentially with all possible follow-up questions listed, 
and written instructions guided participants through which items they should answer or ignore. Prompts elicited information including type of RLX, its location, the decision made and information used to make the decision (see Table 2). The survey focused on situations in which a train was approaching because our previous research has provided detailed data on drivers' behaviour at RLXs when trains are absent (Lenné, Beanland, et al. 2013; Lenné, Salmon, et al. 2013; Salmon, Beanland, et al. 2013) and comparing train-present and train-absent conditions (Salmon, Lenné, Beanland, et al. 2014; Young et al. 2014; Young et al. 2015).

[TABLE 2 HERE]

\subsection{Procedure}

Prospective participants responded to recruitment notices in local newspapers and online newsletters, including motorcycling and bicycling groups, and were prescreened against inclusion criteria. Eligible participants nominated whether they preferred online or paper surveys. Online, 179 participants completed the demographic questionnaire and were given access to daily questionnaires; 23 withdrew or failed to access the questionnaires (13\% attrition). For the paper mode, 15 participants were mailed all questionnaires with a reply-paid envelope; 5 did not respond (33\% attrition). Participants were asked to complete daily questionnaires each night, or as soon as possible thereafter, to maximise reporting accuracy. Online participants were sent email reminders if they missed days or stopped submitting daily questionnaires, which likely explains differential attrition rates between survey modalities.

\subsection{Data analysis}

For each prompt, participants selected one or more options to indicate variables that influenced their decision-making. To ensure sufficient sample sizes, only variables 
endorsed by $\geq 10 \%$ of participants were included in analyses. Logistic regression was used to calculate odds ratios (OR) reflecting whether each variable differed between road user groups, or with decision made at the RLX. Preliminary descriptive analysis of this data has been reported by Beanland et al. (2013); the current paper provides more comprehensive analysis.

\section{Results}

\subsection{Completion Rates}

Participants completed 2086 daily diary entries $(M=12.6$ each $)$. Completion rates did not vary between road user groups, $F(3,162)=1.14, p=.335$. Overall, 445 entries $(21 \%)$ contained a detailed description of an RLX encounter involving a train and/or activated RLX signals: 134 encounters by 41 drivers; 87 encounters by 31 motorcyclists; 85 encounters by 32 cyclists; 139 encounters by 35 pedestrians. Most encounters occurred in metropolitan Melbourne (see Fig. 4), which is unsurprising given the higher frequency of both road and rail traffic in metropolitan areas.

[FIG 4 HERE]

\subsection{Exposure}

Participants' self-reported average weekly travel time using their nominated transport mode $(M=9.2$ hours, $S D=5.4$, range: $2-30)$ did not differ between groups, $F(3,161)=2.24, p=.085$, but analysis of trip frequency revealed differential travel patterns (see Fig. 3A). All participants travelled more on weekdays vs. weekends, $F(1,149)=40.31, p<.001, \eta_{\mathrm{p}}{ }^{2}=.21$. This effect was most pronounced for motorcyclists and cyclists, resulting in a significant group $\times$ day interaction, $F(1,149)=$ $2.94, p<.035, \eta_{\mathrm{p}}{ }^{2}=.06$, and a main effect of group, $F(3,149)=28.71, p<.001, \eta_{\mathrm{p}}{ }^{2}=$ .37 . Overall these patterns suggest the sample was primarily commuters. 


\section{[FIG 3 HERE]}

Exposure to RLXs was calculated separately for weekdays and weekends (see Fig. 3B). All road user groups made more RLX encounters on weekdays vs. weekends, $F(1,148)=38.24, p<.001, \eta_{\mathrm{p}}{ }^{2}=.21$; again, this suggests a commuter sample. Car drivers reported more RLX encounters (1.7 crossings/day) than cyclists (1.2), motorcyclists $(1.1)$ or pedestrians $(0.9), F(3,148)=8.75, p<.001, \eta_{\mathrm{p}}{ }^{2}=.15$.

\subsection{Type of $R L X$}

RLXs were broadly classified as: active, including road crossings with flashing lights and/or booms (see Fig. 1B), and pedestrian crossings with automatic gates (see Fig. 2B); or passive, including road crossings with Stop or Give Way signs (see Fig. 1A) and pedestrian crossings without automatic gates (see Fig. 2A). All train encounters by motorists and most by cyclists (97\%) and pedestrians $(91 \%)$ occurred at active RLXs.

\subsection{Conditions when approaching $R L X$}

Many participants encountered complex conditions when approaching the RLX, including: heavy traffic (50\%); being first at the RLX (26\%); pedestrians nearby (24\%); merging traffic (19\%); stopping or turning immediately after $(16 \%)$ or before $(15 \%)$ the RLX; cyclists nearby (11\%); and being in a hurry (11\%). Drivers were less likely than other road users $(13 \%$ vs. $32 \%)$ to be the first in the queue at the RLX, $\chi^{2}(1)=11.84$, $p=.001$, OR $0.37, \mathrm{CI}_{95 \%}[0.21,0.65]$. Non-motorists were more likely than motorists to report being in a hurry $(16 \%$ vs. $5 \%), \chi^{2}(1)=10.50, p=.001$, OR $3.3, \mathrm{CI}_{95 \%}[1.6,6.7]$, and seeing pedestrians $(31 \%$ vs. $16 \%), \chi^{2}(1)=14.10, p<.001, \mathrm{OR} 2.4, \mathrm{CI}_{95 \%}[1.5,3.9]$, or cyclists near the RLX $(16 \%$ vs. $5 \%), \chi^{2}(1)=14.55, p<.001$, OR 4.0, $\mathrm{CI}_{95 \%}[2.0,8.1]$. 
It was rare for participants to be talking to a passenger or companion $(5 \%)$, talking on a phone (2\%), texting or looking up information $(1 \%)$ or using another portable device (7\%). Pedestrians were more likely than drivers (30\% vs. $2 \%$ ) to report using a phone or portable device, $\chi^{2}(1)=19.90, p<.001$, OR 27.2, $\mathrm{CI}_{95 \%}[6.4,116.1]$. No motorcyclists and $<4 \%$ of cyclists reported using a portable device.

\subsection{Decision made}

Decision made was categorised as "crossed before train", "crossed after train" or “changed route". In most encounters $(n=401,90 \%)$ participants crossed after the train, defined as waiting until after the train had passed, which constitutes compliance with warning signals and road rules. In 40 encounters (10\%) participants crossed before the train, which included both crossing after the signals were activated but before the train was visible, and crossing directly in front of a visible train. Both actions constitute noncompliance. ${ }^{1}$ Changing route involved making a U-turn or turning down a side street with the explicit purpose of avoiding waiting at the RLX. Only four encounters (1\%) involved participants who changed route; due to the small sample, these incidents were excluded from statistical analyses.

Participants were less likely to cross before the train when in heavy traffic, but were more likely to cross before the train when they arrived first at the RLX, or felt time pressure (see Table 3). Pedestrians were more likely than other road users to cross

${ }^{1}$ The Victorian Road Safety Road Rules 2009 (S.R. No. 94/2009) state that: “A driver must not enter a level crossing if-

(a) warning lights (for example, twin red lights or rotating red lights) are operating or warning bells are ringing; or

(b) a gate, boom or barrier at the crossing is closed or is opening or closing; or

(c) a train or tram is on or entering the crossing; or

(d) a train or tram approaching the crossing can be seen from the crossing, or is sounding a warning, and there would be a danger of a collision with the train or tram if the driver entered the crossing; or

(e) the driver cannot drive through the crossing because the crossing, or a road beyond the crossing, is blocked." 
before a train $(19 \%$ vs. $4 \%), \chi^{2}(1)=18.90, p<.001$, OR $4.9, \mathrm{CI}_{95 \%}[2.4,9.9]$.

Participants were more likely to cross before the train at passive vs. active RLXs, but after factoring in road user group this relationship was not statistically significant since pedestrians were more likely to cross at passive RLXs, $\chi^{2}(1)=2.65, p=.104$, OR 2.6, $\mathrm{CI}_{95 \%}[0.8,8.4]$.

[TABLE 3 HERE]

\subsubsection{Critical cues and influencing factors associated with decision-making}

Use of critical cues, information sources and influencing factors varied with decision made. Participants who crossed before the train were more likely to report seeing a train as the first cue that alerted them to the approaching train, $\chi^{2}(1)=7.89$, $p=.005$, OR 3.2, $\mathrm{CI}_{95 \%}[1.4,7.3]$. Response patterns were broadly similar for the information sources and influencing factors prompts, so results are reported only for influencing factors. As shown in Table 3, participants who crossed before a train were less likely to report that their decision was influenced by the behaviour of vehicles and the presence or operation of active signals such as flashing lights, boom barriers and bells.

\subsubsection{Knowledge use associated with decision-making}

Participants who crossed before vs. after the train differed in experience or knowledge they drew upon to make their decision (see Table 3). Participants who crossed before the train were more likely to use knowledge of that specific RLX (i.e., previous crossings there) and knowledge of their ability to accelerate or stop rapidly, but were less likely to draw on knowledge of road rules or RLXs in general. 


\subsubsection{Conceptual and mental models associated with decision-making}

Most participants $(87 \%)$ reported they did not consider potential consequences of their decision before acting. Interestingly, participants were more likely to report considering the consequences of their decision if they crossed before vs. after the train $(38 \%$ vs. $11 \%), \chi^{2}(1)=20.06, p<.001$, OR 5.1, $\mathrm{CI}_{95 \%}[2.5,10.5]$. Among participants who failed to consider consequences, most (97\%) said that it was an automatic response but $3 \%$ reported that they had insufficient time to think.

Finally, participants who crossed before vs. after the train were more likely to describe alternative situations in which they might have made a different decision $(40 \%$ vs. $18 \%), \chi^{2}(1)=10.25, p=.001$, OR 3.0, $\mathrm{CI}_{95 \%}[1.5,6.0]$. The most common alternative was that they would have stopped if the signals had been on for longer and/or if they had more time (i.e., farther away when signals activated, not in a hurry). Other potential deterrents to crossing before a train (all nominated by pedestrians) included if police/enforcement officers had been present, if it was not raining, or if they could see a train approaching.

\subsection{Differences between road users}

Several differences emerged between road user groups, especially comparing pedestrians and motorists. Pedestrians (44\%) were more likely than other road users $(20 \%)$ to report time pressure, $\chi^{2}(1)=15.78, p<.001$, OR $2.5, \mathrm{CI}_{95 \%}[1.6,4.0]$. As noted above, pedestrians were also more likely to cross before a train. The following subsections highlight key differences between road users, controlling for decision made (i.e., whether they crossed before or after the train). 


\subsubsection{Critical cues associated with road user group}

The cues that most frequently alerted participants to the train or activated warnings were flashing lights (39\%), bells (25\%), and seeing a train (10\%). The cue seeing a train did not differ between groups, but other critical cues differed between motorised and non-motorised individuals. Compared to drivers and motorcyclists, pedestrians and cyclists were less likely to use flashing lights as a cue (23\% vs. $55 \%)$, $\chi^{2}(1)=40.04, p<.001$, OR $0.26, \mathrm{CI}_{95 \%}[0.17,0.40]$, and more likely to use bells $(41 \%$ vs. $8 \%), \chi^{2}(1)=52.42, p<.001$, OR 8.2, $\mathrm{CI}_{95 \%}[4.6,14.4]$.

\subsubsection{Influencing factors associated with road user group}

The most frequently reported factors influencing decisions across road user groups were: presence/operation of boom barriers; presence/operation of bells; experience at this RLX; presence/operation of flashing lights; seeing a train; behaviour of vehicles; experience at other RLXs; traffic lights; hearing a train; signs saying "Railway Crossing"; and presence/operation of pedestrian gates. Of these factors, experience at this RLX was the only one that did not differ between road users. Among drivers the most important influencing factors were booms (70\%), flashing lights (53\%), behaviour of vehicles (44\%) and bells (39\%). Motorcyclists reported similar influences to drivers (see Table 4), but more likely to be influenced by bells, OR 2.3, $\mathrm{CI}_{95 \%}[1.3$, 4.1], and experience at other RLXs, OR 3.6, $\mathrm{CI}_{95 \%}[1.9,6.6]$.

\section{[TABLE 4 HERE]}

There were notable differences in factors that influenced motorised vs. nonmotorised road users (see Table 4). Cyclists more likely than drivers to be influenced by auditory factors, namely bells (OR 1.9, $\left.\mathrm{CI}_{95 \%}[1.1,3.4]\right)$ and hearing a train (OR 6.0, $\left.\mathrm{CI}_{95 \%}[2.1,17.0]\right)$, and less likely to be influenced by visual factors including behaviour of vehicles (OR 0.2, $\left.\mathrm{CI}_{95 \%}[0.1,0.4]\right)$, signs (OR 0.2, $\left.\mathrm{CI}_{95 \%}[0.1,0.6]\right)$, and flashing 
lights (OR 0.4, $\left.\mathrm{CI}_{95 \%}[0.3,0.8]\right)$. Pedestrians were less likely than drivers to be influenced by behaviour of vehicles (OR $\left.0.2, \mathrm{CI}_{95 \%}[0.1,0.4]\right)$, and road infrastructure including booms (OR 0.2, $\left.\mathrm{CI}_{95 \%}[0.1,0.4]\right)$, traffic lights (OR 0.2, $\mathrm{CI}_{95 \%}[0.1,0.4]$ ), flashing lights (OR 0.3, $\mathrm{CI}_{95 \%}[0.2,0.6]$ ), and signs (OR 0.4, $\left.\mathrm{CI}_{95 \%}[0.2,0.8]\right)$. However, pedestrians were more likely than drivers to be influenced by operation of pedestrian gates (OR 27.2, $\left.\mathrm{CI}_{95 \%}[6.4,116.2]\right)$, hearing a train (OR 10.0, $\left.\mathrm{CI}_{95 \%}[3.7,26.5]\right)$, and seeing a train $\left(\mathrm{OR} 3.0, \mathrm{CI}_{95 \%}[1.7,5.1]\right)$.

When asked to specify the most important factor that influenced their decision, drivers (31\%) and cyclists (29\%) most commonly nominated presence/operation of booms, whereas motorcyclists most frequently nominated flashing lights (33\%) and pedestrians most commonly nominated seeing a train (22\%).

\subsubsection{Knowledge use associated with road user group}

Participants reported utilising considerable knowledge and experience to make their decision, including knowledge about: RLXs; warning signal reliability; road rules; road conditions; train speeds and behaviour; rail accidents and near-misses; their own acceleration/braking capabilities; and vehicle size. Drivers were most likely to use knowledge and experience of road rules (66\%), RLXs in general (64\%), and this particular RLX (45\%). Cyclists relied on similar knowledge to drivers, but were more likely to draw on knowledge of rail accidents, $\chi^{2}(1)=10.03, p=.002$, OR $2.8, \mathrm{CI}_{95 \%}$ $[1.5,5.4]$

Most differences between road users involved motorcyclists and pedestrians (see Table 5). Compared to drivers and cyclists, motorcyclists and pedestrians were less likely to use knowledge of road rules, $\chi^{2}(1)=26.55, p<.001$, OR $0.35, \mathrm{CI}_{95 \%}[0.24$, 0.52 ], and more likely to use knowledge of train speeds, $\chi^{2}(1)=45.20, p<.001$, OR 8.7, $\mathrm{CI}_{95 \%}[4.6,16.3]$, when making their decision. Motorcyclists were also more likely than 
drivers to use knowledge of acceleration/braking capabilities, $\chi^{2}(1)=9.15, p=.002$, OR 2.8, $\mathrm{CI}_{95 \%}[1.4,5.3]$, and road surface $\chi^{2}(1)=11.74, p=.001, \mathrm{OR} 2.9, \mathrm{CI}_{95 \%}[1.6,5.3]$. [TABLE 5 HERE]

\subsubsection{Conceptual and mental models associated with road user group}

Responses to the "mental models" and "conceptual" probes suggested drivers possess less complex mental models than other road users, especially motorcyclists. Motorcyclists and pedestrians (20\%) were more likely than drivers and cyclists (5\%) to consider decision consequences, $\chi^{2}(1)=15.86, p<.001$, OR 4.1, $\mathrm{CI}_{95 \%}[2.1,8.3]$. Similarly, two-wheeler users (motorcyclists and cyclists; 28\%) were more likely to describe situations in which their decision would have turned out differently, compared to both drivers and pedestrians $(15 \%), \chi^{2}(1)=12.01, p=.001$, OR $2.4, \mathrm{CI}_{95 \%}[1.5,3.9]$.

When considering alternative actions, several drivers who stopped at the RLX indicated they might cross before the train if they were closer when the signals activated or if it was an emergency/time-sensitive situation. Cyclists suggested they would only cross if the signals were not active, if signals were active but booms/gates had not yet closed, if signals appeared to be faulty, or if they were in a hurry. Pedestrian alternatives focused on sight distance and their ability to run across the tracks before the train arrived; if they could see farther down the tracks and/or could not see a train, they would be more inclined to proceed. Motorcyclists were distinct from other road users in that they suggested not only situations in which they would/would not cross, but also alternative behaviours when stopped (e.g., if stopped for longer they might turn off the engine; depending on traffic they would/would not filter through the queue). Situations that would prompt a motorcyclist to cross before a train were broadly similar to drivers and cyclists: if there was no train, if they were close to the tracks, if booms had not yet descended, or if signals appeared faulty. 


\section{Discussion}

The current study provides much-needed insight into road users' decision-making and cognitive processes at RLXs in the presence of a train and/or activated signals. Further, the study demonstrates the potential usefulness of CDM-based surveys for examining decision-making processes in large samples, confirming previous findings by Walker et al. (2009). Most individuals complied with RLX signals and rules, but compliance varied between road users: pedestrians were nearly five times more likely than other road users to be noncompliant. Noncompliance was also associated with being the first to arrive at the crossing, experiencing time pressure and not being in heavy traffic.

Reasons for noncompliance differ between road users: pedestrians cross before a train when in a hurry, particularly if they adequate ability to run across the tracks and sufficient visibility to assess train time-to-arrival, whereas cyclists' and motorists' main reason for noncompliance was that when the signals activated they were too close to the RLX to stop safely. Our results confirm that different road users negotiate RLXs in different ways: they draw on varying personal experience, identify distinct cues and possess different situation awareness. The following subsections elaborate on the key differences between road user groups.

\subsection{Influence by other agents}

RLX systems show some evidence of distributed situation awareness, in that motorists' and cyclists' decision-making is guided by both active infrastructure signals and behaviour of other road users (i.e., signalling that a train is approaching). Drivers especially are strongly influenced by other motorists. These findings are broadly consistent with previous research from on-road studies, which have revealed that drivers rely on active infrastructure for information when they are first in the queue, and other road users when they are farther back (Salmon, Beanland et al. 2013; Salmon, Lenné, 
Beanland et al. 2014; Young et al. 2014; Young et al. 2015). Although it is encouraging that road users' support each other, this is contingent on other road users being present, which cannot be guaranteed. Consistent with this, noncompliance was more likely when there were few or no other road users nearby. Whereas motorists and to a lesser extent cyclists influence each other at RLXs, pedestrians appear to mostly operate independently from other users, relying predominantly on their own situation awareness and assessment (e.g., seeing or hearing a train) rather than taking cues from others or active infrastructure. Interestingly, one possible deterrent to violating warnings, nominated by pedestrians, was the presence of enforcement officers. However, knowledge of enforcement activities or having been fined previously did not emerge as a significant influence on behaviour, suggesting that enforcement is only influential when directly present at the RLX, which is not achievable at all locations.

\subsection{Importance of physical barriers}

Active crossings appear to operate in a way that facilitates safe decisions by most motorists: they proceed if they are very close to the tracks when signals activate, but stop if they are farther away. Most drivers consider a narrow range of possible actions: they stop or proceed depending on proximity to the crossing, with a minority re-routing to avoid an active RLX. Booms and other vehicles are the most influential factors that determine whether a driver will cross; notably both physically prohibit proceeding. Two-wheelers can physically circumnavigate booms and vehicles; however, most motorcyclists and cyclists who reported filtering through traffic aimed to reach the front of the queue, not to violate barriers. The influence of physical barriers on motorists' decision-making suggests that barriers promote safer decisions. Consistent with this, incident data indicates boom-protected RLXs yield the best safety performance (e.g., Saccomanno, Park, and Fu 2007). Further, absence of booms was 
identified as a key contributory factor in the Kerang crash (Salmon, Read, et al. 2013). Finally, the importance of physical barriers is reinforced by the finding that pedestrians (for whom barriers are easy to circumvent) are most likely to violate RLX warnings.

\subsection{Auditory versus visual information}

A striking finding is the relative importance of visual versus auditory information for different road users. Auditory information (e.g., bells, train horn) was most influential for pedestrians and cyclists, whereas motorised road users utilised visual information including observing other vehicles, active infrastructure and passive signs. It is concerning that many pedestrians were distracted on approach to the RLX (e.g., phone conversations, listening to music), as auditory distractions may attenuate RLX signals. Pedestrians' preference for auditory warnings highlights the need to incorporate multiple warning modalities in systems. Auditory warnings are redundant for motorists, since they are consistent with but less salient than visual warnings due to vehicle and helmet sound insulation. For pedestrians, auditory warnings are more useful since they are detectable anywhere proximal to the crossing, whereas visual warnings are detectable only when directly within sight.

The primary visual information source used by pedestrians was sighting the train, used in conjunction with other factors (e.g., ability to run across tracks) in order to judge whether they had sufficient time to cross. Seeing the train provides additional information that other visual cues lack, namely time-to-arrival. Coupled with the fact that pedestrians were more likely to report time pressure, this implies that the decision to cross is jointly influenced by time pressure and the train's estimated time-to-arrival. This is concerning given research demonstrating that observers are poor at estimating train speeds (Clark, Perrone, and Isler 2013). One prospect for future countermeasures is active RLXs that explicitly display train time-to-arrival; however, this could facilitate 
rather than deter risky gap acceptance. When evaluating similar designs for road intersections, Creaser et al. (2007) found that drivers typically disregarded warnings accompanying time-to-arrival estimations (e.g., $\leq 4 \mathrm{~s}=$ stop) because they possess their own intuitions of the time required to negotiate intersections. Thus, while providing time-to-arrival information could support decision-making in situations with limited sight distance, or instances where there are multiple trains approaching, any proposed designs would require rigorous empirical evaluation.

\subsection{Experience and Schemata}

Road users' decisions at RLXs were influenced by their knowledge and experience, especially prior experience with RLXs and knowledge of road rules. Participants were regular RLX users, crossing on average nine RLXs per week, meaning they likely had well-developed anticipatory schemata for negotiating RLXs (Neisser 1976; Plant and Stanton 2013a). Our results suggest that most road users rely on a limited number of cues to determine whether it is safe to proceed at an RLX: typically physical barriers for motorists, or seeing a train for pedestrians. This implies that many road users possess a fairly rigid schema for RLXs, which could be problematic in situations that deviate from expectations, such as when pedestrians cannot see an approaching train, when a driver encounters a passive RLX, or when road users experience a new RLX that operates differently to the ones that their schema is built upon (Salmon, Beanland, et al. 2013; Salmon, Lenné, Beanland, et al. 2014). RLX environments are not homogenous, having diverse warnings, varying timings, and unique surroundings (e.g., buildings, vegetation). The enormous influence of experience on decision-making suggests a more uniform approach to RLX design would be beneficial. Previous research has indicated inadequate schema, particularly those developed through homogenous experiences, can contribute to RLX collisions (Salmon, 
Read, et al. 2013) and train driver behaviour (Stanton and Walker 2011). This highlights that modifying RLX infrastructure will not necessarily prevent collisions, unless interventions are specifically designed to target users' expectations.

\subsection{Limitations}

Although the current study provides unique insight into factors that shape decision-making at RLXs, emphasising road users' diversity of experiences, there are some limitations that affect the generalizability of our conclusions. Our sample consisted of frequent RLX users, meaning it comprised individuals who possess a welldeveloped schema for RLXs. Infrequent RLX users may differ in their decision-making; for instance, they may have less rigid expectations and be less likely to make automatic decisions. In addition, retrospective reporting may result in biased or incomplete recall. To minimise this we asked participants to complete the survey each day. Encouragingly, the results for drivers are consistent with concurrent measures recorded during on-road instrumented vehicle studies, such as verbal protocols, eye-movement and head check behaviour (Lenné, Beanland, et al. 2013; Lenné, Salmon, et al. 2013; Salmon, Beanland, et al. 2013; Salmon, Lenné, Beanland, et al. 2014; Young et al. 2014; Young et al. 2015). This suggests that although retrospective self-report methods are not perfect, they provide relatively reliable data. A final limitation is that our sample did not include truck drivers, which is notable in that some recent high-profile fatal RLX crashes involved heavy vehicles (e.g., Salmon, Read, et al. 2013). This occurred for pragmatic reasons, due to difficulties recruiting professional drivers for a longitudinal survey-based study. 


\subsection{Summary and Conclusions}

Overall our findings provide important conclusions regarding the design of RLX environments, revealing that previous experience is a key driver of decision-making and behaviour at RLXs and visual cues are the primary information source for motorists. Booms are particularly influential for drivers, since they form a physical barrier that prohibits crossing, and consequently achieve superior safety performance (Saccomanno, Park, and Fu 2007). Auditory information is rarely used by motorists, since its audibility is too low to be salient, but is commonly used by pedestrians and cyclists.

Together these findings indicate elevated risk for motorists at rural RLXs, particularly passive RLXs and active RLXs without booms. Bells will have minimal impact on decision-making, and road users who do not expect trains in rural areas could fail to detect lights flashing; previous research suggests such expectations can result in "looked-but-failed-to-see" errors when drivers check RLX signals (Salmon, Read, et al. 2013). While failure to notice active signals could occur in any environment, it is mostly likely to remain uncorrected in rural settings that lack booms or other physical barriers, as in the Kerang incident (Salmon, Read, et al. 2013). On this basis, it appears that actively-controlled RLXs that have only flashing lights (no booms), which are found throughout many rural areas, represent an unsafe RLX system. Steps should be taken to develop more appropriate warnings, including warnings that are more visually conspicuous and less susceptible to perceptual errors (e.g., reflective glare interference, looked-but-failed-to-see errors).

Existing pedestrian RLXs also seem to function in a fundamentally unsafe manner, resulting in many pedestrians violating or disregarding warnings. Interestingly, individuals who crossed before the train were more, rather than less, likely to consider the consequences of their actions. The fact that many individuals deliberately disregard RLX warnings suggests that existing RLX systems do not function satisfactorily for 
these users (e.g., wait times are excessive). Some comments indicated that greater enforcement could help, but only if it is physically present when users are tempted to violate RLX rules and warnings. Overall the results regarding pedestrians highlight the need to focus interventions on a broad range of road users, rather than designing systems to meet the needs of motorists.

Recent studies have argued that attempts to improve safety have failed in part because they focus on a single road user, or on a single component of the problem, rather than considering all users and the broader system (Cornelissen et al. 2013; Salmon, Lenné, Walker, et al. 2014). Similarly, our results suggest that interventions designed for a specific road user group will not be effective at reducing RLX collisions across road user groups. Previous research has demonstrated incompatibilities between different road users at road junctions (Salmon, Lenné, Walker, et al. 2014). Future research should extend the current findings to understand the nature of incompatibilities between different road and rail users at RLXs. Overall our results emphasise the importance of designing systems to support cognition and behaviour across the full extent of possible users, in order to ensure a safe system for all.

\section{Acknowledgements}

We gratefully acknowledge the support of the project partners and community participants. Without their valuable input and commitment, this research would not be possible. We also thank Gemma Read, Ashleigh Filtness and Jessica Edquist for their assistance with this project.

\section{Funding}

This research was funded by an Australian Research Council Linkage Grant (LP100200387) to Monash University, the University of the Sunshine Coast and the University of Southampton, along with the following partner organisations: the Victorian Rail Track Corporation, Transport Safety Victoria, Public Transport Victoria, Transport Accident Commission, Roads Corporation (VicRoads) and V/Line Passenger Pty Ltd. Vanessa Beanland is supported by an Australian Research Council Discovery Early Career Researcher Award (DE150100083). Paul Salmon is 
supported by an Australian Research Council Future Fellowship (FT140100681). The views expressed in this article are those of the authors and not necessarily the views of the funding bodies or partner organisations. 
Table 1. Participant demographic characteristics by road user type.

\begin{tabular}{|c|c|c|c|c|}
\hline & Car drivers & Motorcyclists & Cyclists & Pedestrians \\
\hline Sample size $(n)$ & 50 & 39 & 42 & 35 \\
\hline \multicolumn{5}{|l|}{ Area of residence ${ }^{* * *}$} \\
\hline Metropolitan Melbourne & $31(62 \%)$ & $28(72 \%)$ & $41(98 \%)$ & $33(94 \%)$ \\
\hline Regional Victoria & $19(38 \%)$ & $11(28 \%)$ & $1(2 \%)$ & $2(6 \%)$ \\
\hline \multicolumn{5}{|l|}{$\operatorname{Sex}^{* * *}$} \\
\hline Male & $18(36 \%)$ & $33(85 \%)$ & $29(69 \%)$ & $14(40 \%)$ \\
\hline Female & $32(64 \%)$ & $6(15 \%)$ & $13(31 \%)$ & $21(60 \%)$ \\
\hline \multicolumn{5}{|l|}{ Age in years ${ }^{* *}$} \\
\hline Mean age (SD) & $37.2(13.8)$ & $46.3(9.8)$ & $41.0(11.8$ & $35.5(13.2)$ \\
\hline Age range & $18-71$ & $29-65$ & $25-65$ & $18-64$ \\
\hline $\begin{array}{l}\text { Mean years of licensure } \\
\text { (SD) }\end{array}$ & $17.9(14.0)$ & $18.6(14.8)$ & $\mathrm{n} / \mathrm{a}$ & $\mathrm{n} / \mathrm{a}$ \\
\hline
\end{tabular}


Table 2. List of CDM probes and questions used.

\begin{tabular}{|c|c|c|}
\hline Probe & Question & Answer type \\
\hline \multirow[t]{3}{*}{$\begin{array}{l}\text { Incident } \\
\text { description }\end{array}$} & $\begin{array}{l}\text { Please describe the situation when you } \\
\text { approached the rail level crossing. }\end{array}$ & Open-ended \\
\hline & $\begin{array}{l}\text { Describe how you knew whether a train was } \\
\text { approaching. }\end{array}$ & Open-ended \\
\hline & $\begin{array}{l}\text { Describe what you did at the rail level } \\
\text { crossing and why you did it. }\end{array}$ & Open-ended \\
\hline $\begin{array}{l}\text { Goal } \\
\text { specification }\end{array}$ & $\begin{array}{l}\text { What were your specific goals when you } \\
\text { approached this level crossing? }\end{array}$ & Open-ended \\
\hline Assessment & $\begin{array}{l}\text { What were the conditions at the time of this } \\
\text { rail level crossing encounter? }\end{array}$ & $\begin{array}{l}\text { Closed-ended; multiple } \\
\text { options allowed }\end{array}$ \\
\hline $\begin{array}{l}\text { Cue } \\
\text { identification }\end{array}$ & $\begin{array}{l}\text { What first alerted you to the presence of the } \\
\text { train or the activated warnings? }\end{array}$ & $\begin{array}{l}\text { Closed-ended; one } \\
\text { option allowed }\end{array}$ \\
\hline $\begin{array}{l}\text { Situation } \\
\text { awareness }\end{array}$ & $\begin{array}{l}\text { What information did you use when you } \\
\text { made your decision to stop or proceed at this } \\
\text { level crossing? }\end{array}$ & $\begin{array}{l}\text { Closed-ended; multiple } \\
\text { options allowed }\end{array}$ \\
\hline $\begin{array}{l}\text { Information } \\
\text { integration }\end{array}$ & $\begin{array}{l}\text { What was the most important piece of } \\
\text { information you used when you made your } \\
\text { decision to stop or proceed at this level } \\
\text { crossing? }\end{array}$ & $\begin{array}{l}\text { Closed-ended; one } \\
\text { option allowed }\end{array}$ \\
\hline $\begin{array}{l}\text { Situation } \\
\text { assessment }\end{array}$ & $\begin{array}{l}\text { Was there any other information that would } \\
\text { have been useful when making your } \\
\text { decision to stop or proceed at this level } \\
\text { crossing? }\end{array}$ & $\begin{array}{l}\text { Combined closed- and } \\
\text { open-ended }\end{array}$ \\
\hline \multirow[t]{2}{*}{$\begin{array}{l}\text { Influencing } \\
\text { factors }\end{array}$} & $\begin{array}{l}\text { What factors influenced your decision to } \\
\text { stop or proceed at this level crossing? }\end{array}$ & $\begin{array}{l}\text { Closed-ended; multiple } \\
\text { options allowed }\end{array}$ \\
\hline & $\begin{array}{l}\text { What was the most important factor that } \\
\text { influenced your decision to stop or proceed } \\
\text { at this level crossing? }\end{array}$ & $\begin{array}{l}\text { Closed-ended; one } \\
\text { option allowed }\end{array}$ \\
\hline $\begin{array}{l}\text { Decision- } \\
\text { making }\end{array}$ & $\begin{array}{l}\text { How much time pressure was involved in } \\
\text { making your decision to stop or proceed at } \\
\text { this level crossing? }\end{array}$ & $\begin{array}{l}\text { Closed-ended; one } \\
\text { option allowed }\end{array}$ \\
\hline $\begin{array}{l}\text { Mental } \\
\text { models }\end{array}$ & $\begin{array}{l}\text { Did you think about the potential } \\
\text { consequences of your decision to stop or } \\
\text { proceed before you made it? }\end{array}$ & $\begin{array}{l}\text { Closed-ended; one } \\
\text { option allowed }\end{array}$ \\
\hline Experience & $\begin{array}{l}\text { What previous experience or knowledge did } \\
\text { you use when you made your decision? }\end{array}$ & $\begin{array}{l}\text { Closed-ended; multiple } \\
\text { options allowed }\end{array}$ \\
\hline Conceptual & $\begin{array}{l}\text { Are there any situations in which your } \\
\text { decision would have turned out differently? }\end{array}$ & $\begin{array}{l}\text { Combined closed- and } \\
\text { open-ended }\end{array}$ \\
\hline
\end{tabular}


Table 3. Conditions, influencing factors and knowledge that predicted decision made at RLX.

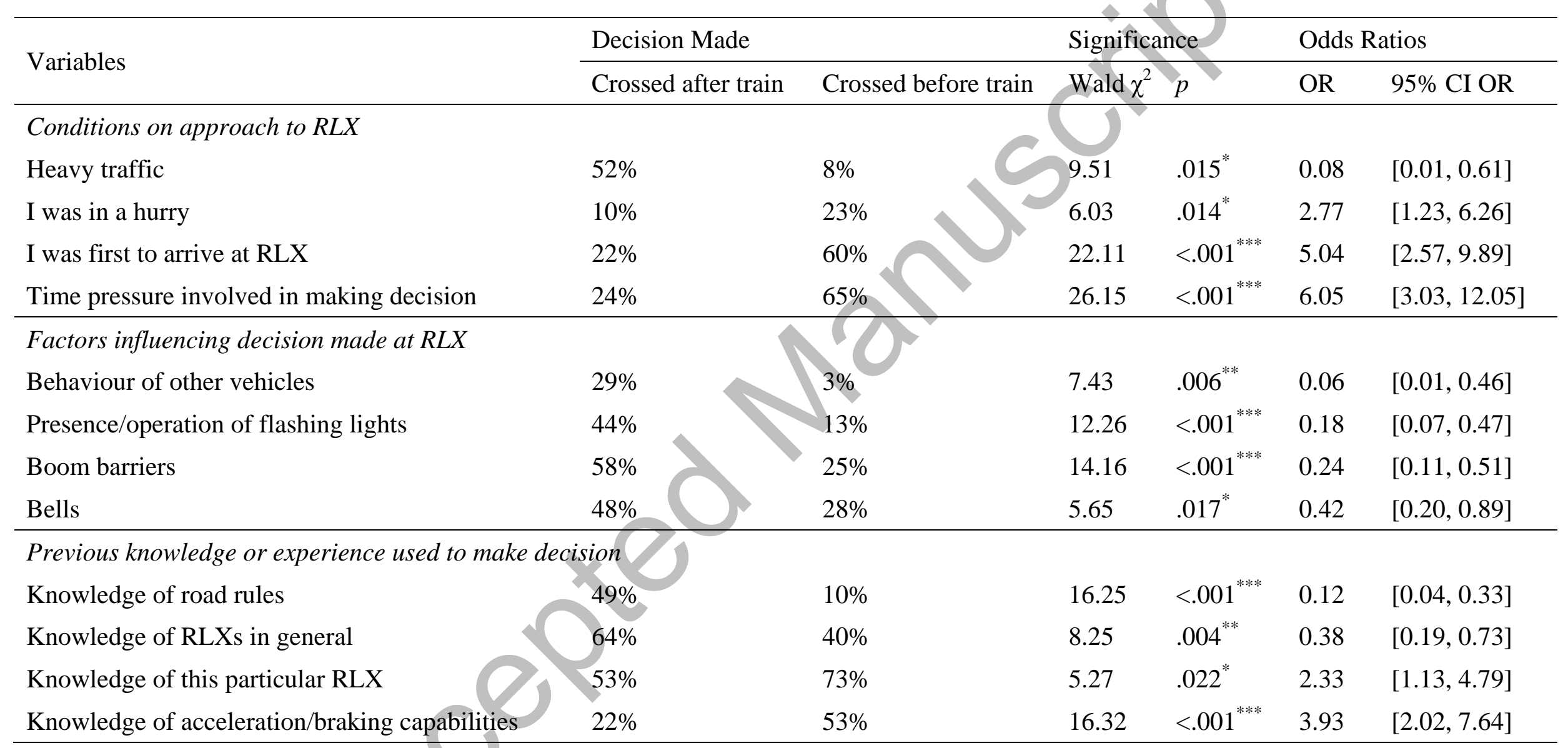

Note. Multiple response options were permitted so columns many not sum to $100 \%$.

${ }_{* *}^{*}<<.05$

$p<.01$

*** $p<.001$ 
Table 4. Factors that influenced decision-making at RLXs, by road user group.

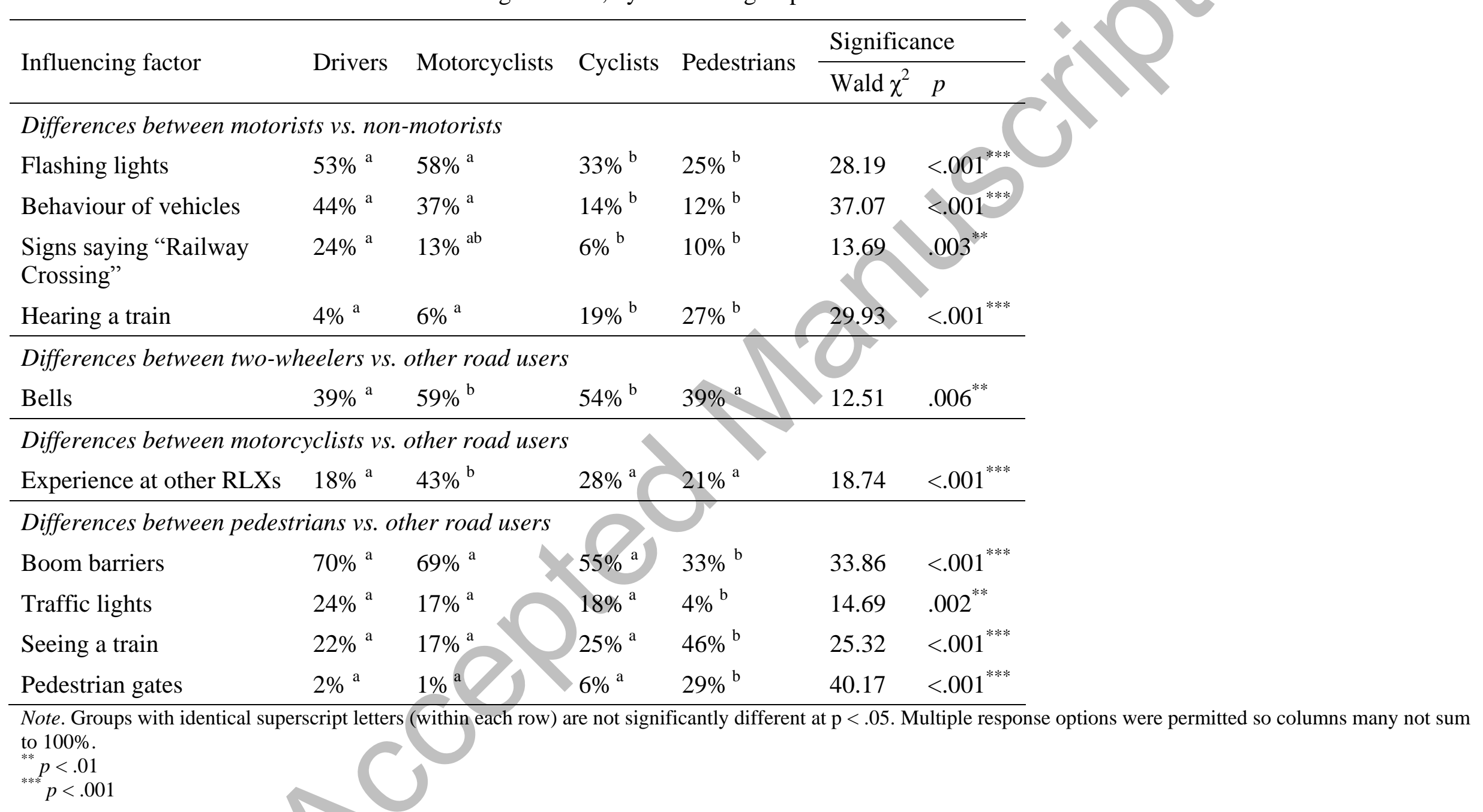


Table 5. Knowledge used to make decisions at RLXs, by road user group.

\begin{tabular}{|c|c|c|c|c|c|c|c|}
\hline \multirow{2}{*}{ Knowledge about... } & \multirow{2}{*}{ Drivers } & \multirow{2}{*}{ Motorcyclists } & \multirow{2}{*}{ Cyclists } & \multirow{2}{*}{ Pedestrians } & \multirow{2}{*}{\multicolumn{3}{|c|}{$\begin{array}{l}\text { Significance } \\
\text { Wald } \chi^{2} p\end{array}$ Group differences }} \\
\hline & & & & & & & \\
\hline Road rules & $66 \%^{a}$ & $51 \%^{b}$ & $51 \%{ }^{\mathrm{ab}}$ & $20 \%{ }^{\mathrm{c}}$ & 43.64 & $<.001^{* * * *}$ & Drivers $>$ Motorcyclists $>$ Pedestrians \\
\hline Road surface condition & $20 \%^{\mathrm{a}}$ & $42 \%^{b}$ & $24 \%^{\mathrm{a}}$ & $24 \%^{\mathrm{a}}$ & 14.13 & $.003^{* *}$ & Motorcyclists $>$ others \\
\hline $\begin{array}{l}\text { Rail accidents or near } \\
\text { misses }\end{array}$ & $17 \%^{a}$ & $21 \%^{a}$ & $35 \%^{b}$ & $19 \%^{a}$ & 11.26 & & Cyclists $>$ others \\
\hline $\begin{array}{l}\text { Acceleration or braking } \\
\text { capabilities }\end{array}$ & $15 \%^{a}$ & $34 \%{ }^{b}$ & $22 \%^{a b}$ & $30 \%$ ab & & & Motorcyclists $>$ Drivers \\
\hline Train speeds & $5 \%{ }^{\mathrm{a}}$ & $24 \%^{\mathrm{b}}$ & $7 \%^{a}$ & $40 \%^{\mathrm{b}}$ & 53.52 & $<.001^{* * *}$ & Motorcyclists \& Pedestrians > others \\
\hline
\end{tabular}

Note. Groups with identical superscript letters (within each row) are not significantly different at $\mathrm{p}<.05$. Multiple response options were permitted so columns many not sum to $100 \%$.

" $p<.05$

$p<.01$

$p<.001$ 
A. Passive Rail Level Crossings - Road

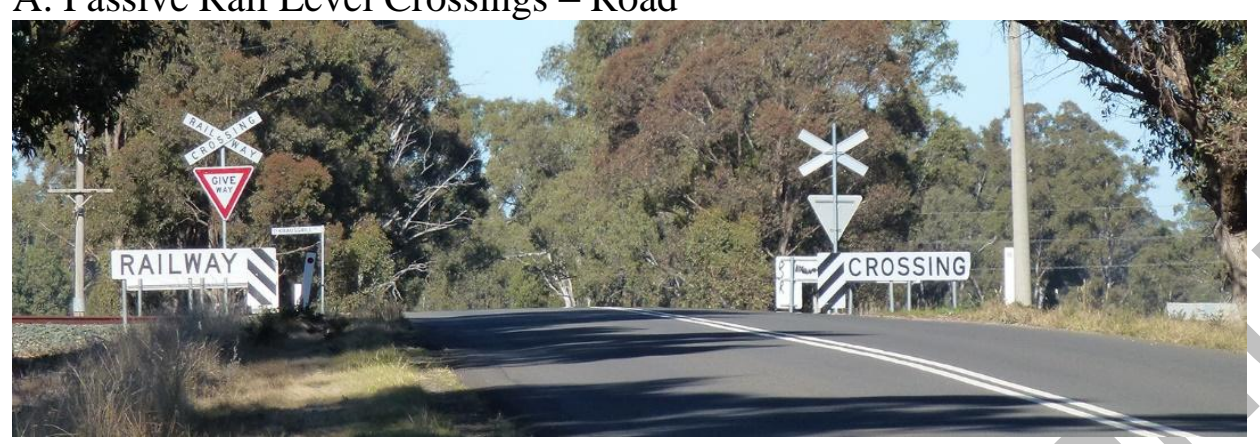

B. Active Rail Level Crossings - Road

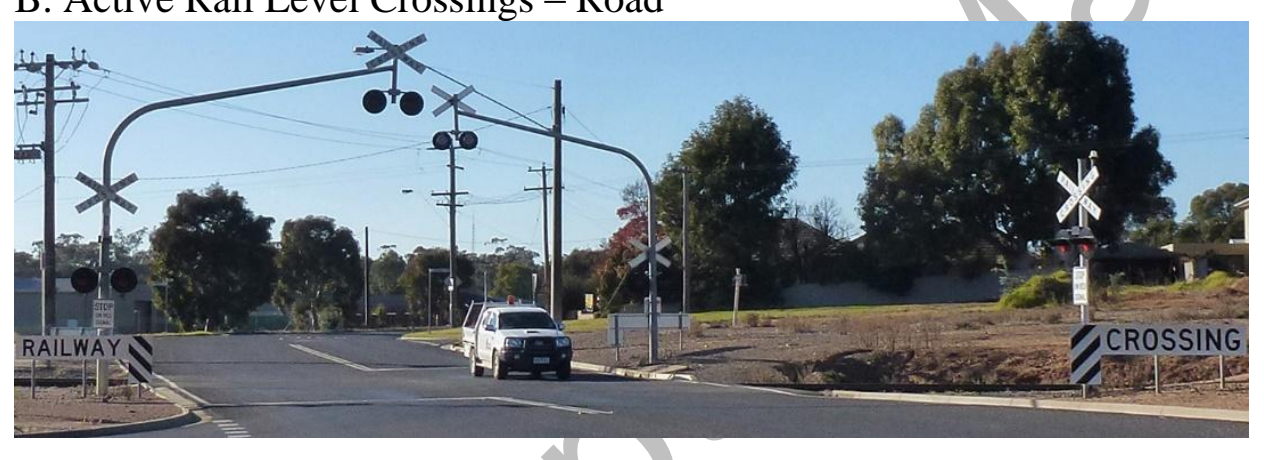

$(3)$
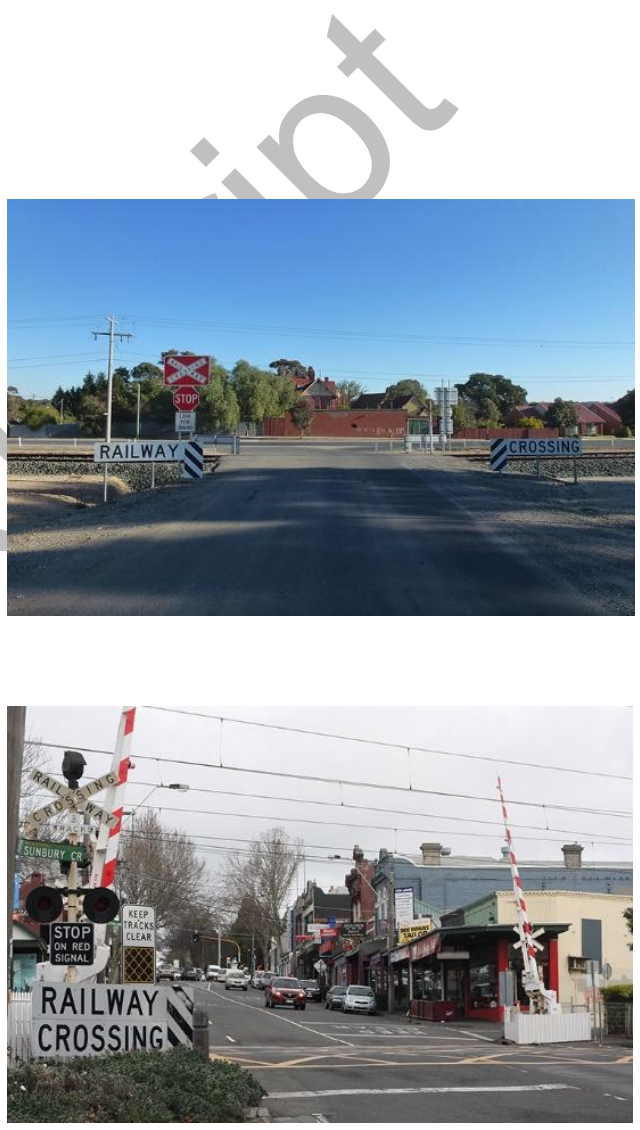

Figure 1. Examples of passive (top row) and active (bottom row) rail level crossings, where the train tracks intersect with roads used by vehicles. Note that some road crossings have adjacent pedestrian crossings; an example is visible in the bottom right photograph. (Refer to online version for colour figures.)

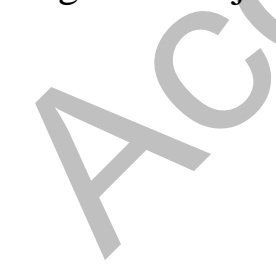


A. Passive Rail Level Crossings - Pedestrian/Cyclist Path
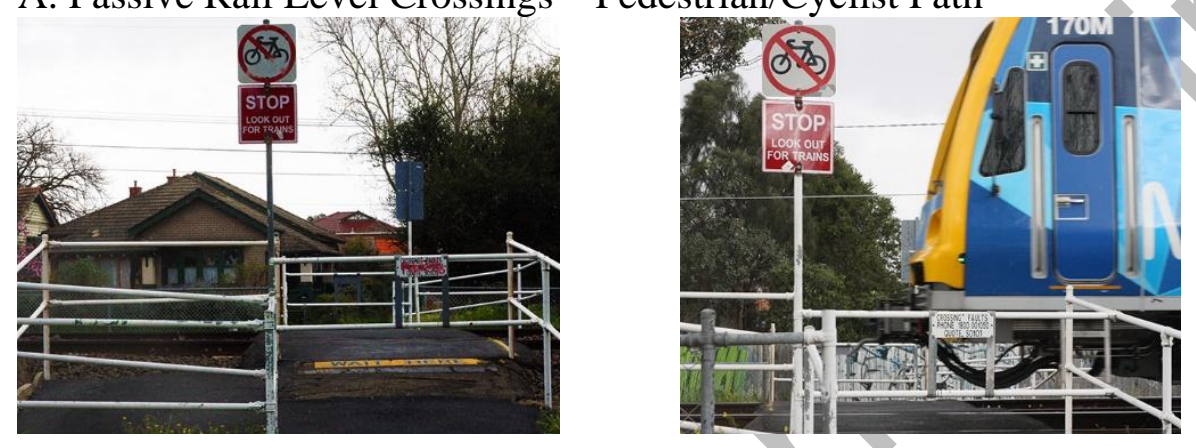

B. Active Rail Level Crossings - Pedestrian/Cyclist Path
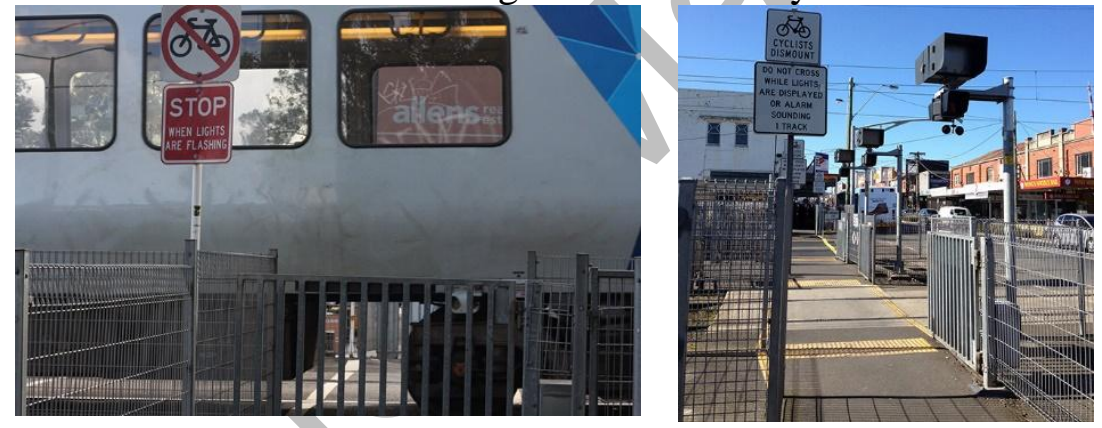

Figure 2. Examples of passive (top row) and active (bottom row) rail level crossings, where the train tracks intersect with footpaths used by pedestrians and cyclists. (Refer to online version for colour figures.)

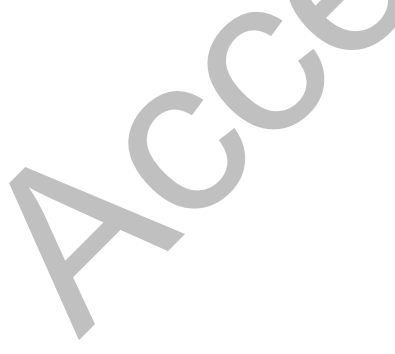



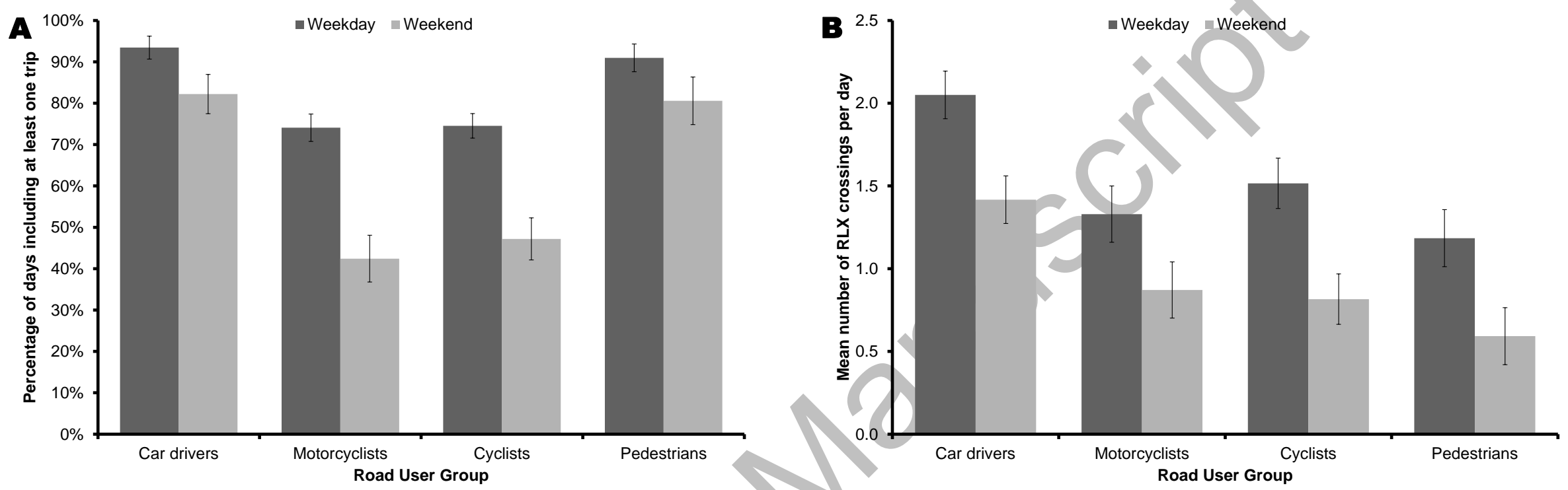

Figure 3. Participants' average daily modal use (A) and number of RLXs crossed (B). 
A

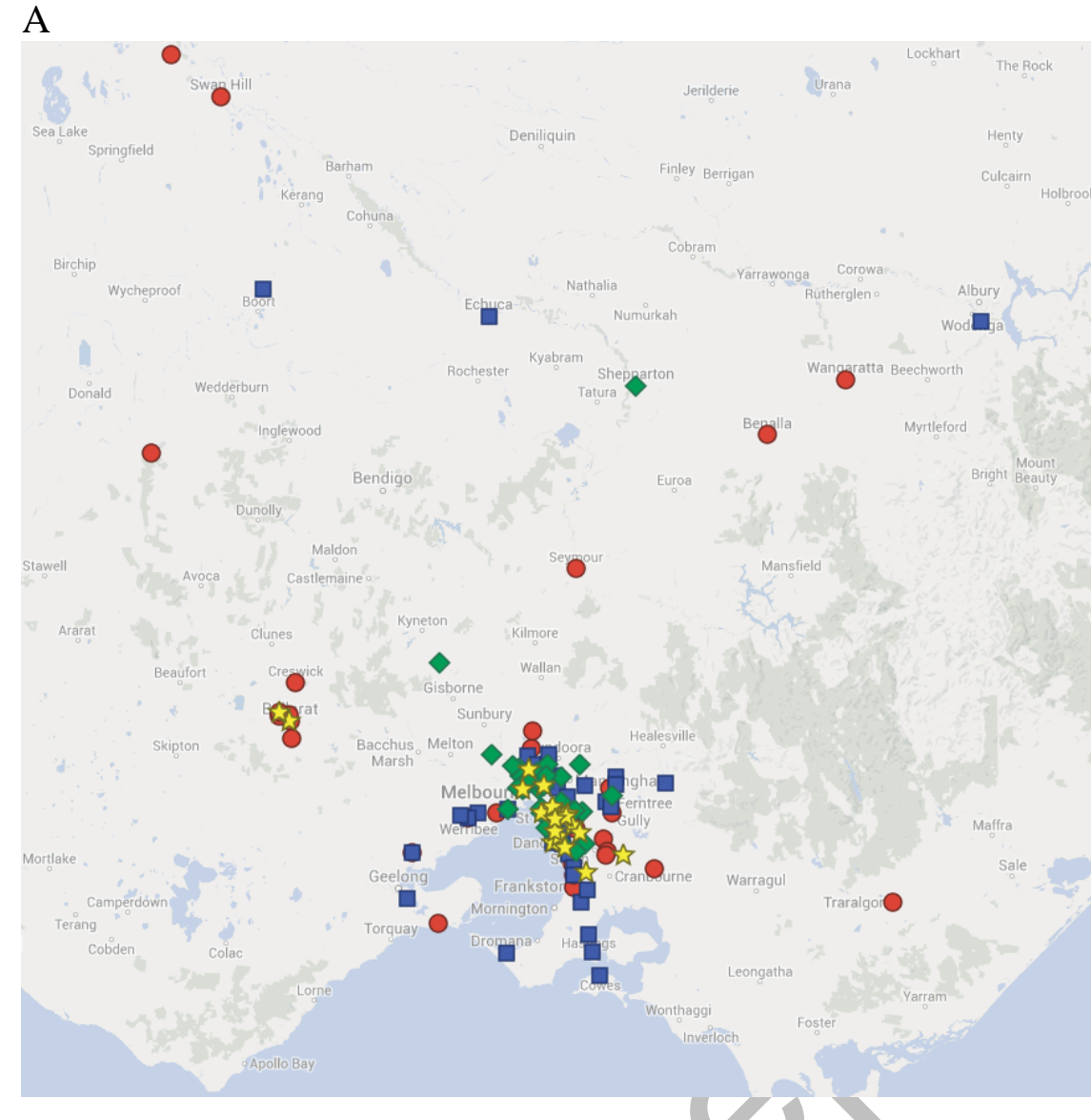

B

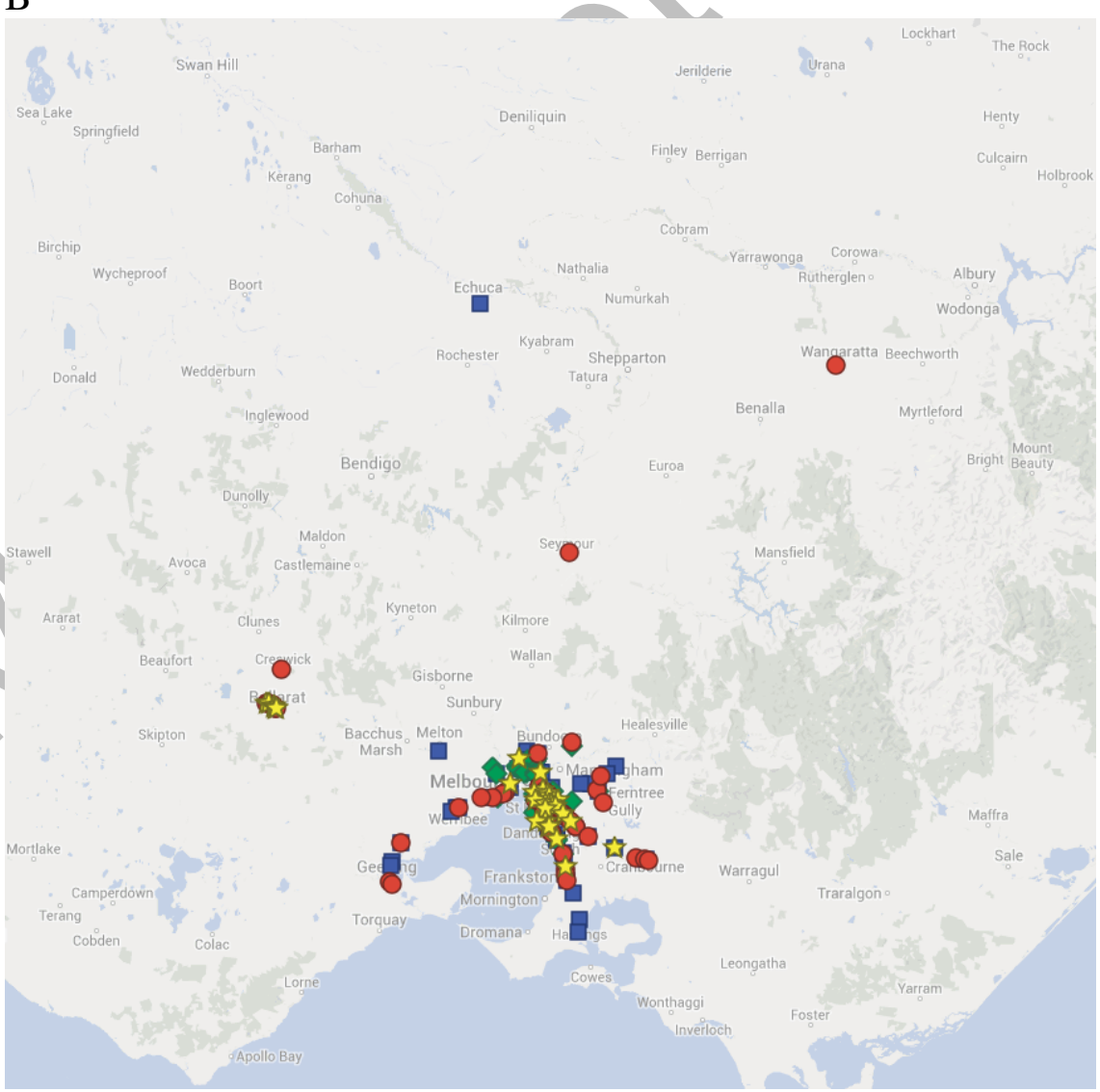

Figure 4. Map of participants' city, suburb or town of residence (A) and locations of RLXs where each encounter occurred (B), by road user. Red circles represent car drivers; blue squares represent motorcyclists; green diamonds represent cyclists; and yellow stars represent pedestrians. (Refer to online version for colour figures.) 


\section{References}

Australian Transport Safety Bureau (ATSB). 2008. Railway level crossing safety bulletin. Canberra, Australia: Australian Transport Safety Bureau.

Beanland, Vanessa, Michael G. Lenné, Paul M. Salmon, and Neville A. Stanton. 2013. "A self-report study of factors influencing decision-making at rail level crossings: Comparing car drivers, motorcyclists, cyclists and pedestrians." In Proceedings of the 2013 Australasian Road Safety Research, Policing \& Education Conference, 1-11. Canberra, Australia: Australasian College of Road Safety.

Booth, T., and M. Balmford. 2010. Railway level crossing incident cosing model: For the Rail Industry Safety and Standards Board (RISSB). Sydney, Australia: LECG.

Caird, J. K., Janet I. Creaser, C. J. Edwards, and R. E. Dewar. 2002. A human factors analysis of highway-railway grade crossing accidents in Canada. Montreal, Canada: Transport Canada.

Cairney, P. 2003. Prospects for improving the conspicuity of trains at passive railway crossings. Canberra, Australia: Australian Transport Safety Bureau.

Clark, Helen E., John A. Perrone, and Robert B. Isler. 2013. "An illusory size-speed bias and railway crossing collisions." Accident Analysis \& Prevention no. 55:226-231. doi: 10.1016/j.aap.2013.02.037.

Cornelissen, Miranda, Paul M. Salmon, Roderick McClure, and Neville A. Stanton. 2013. "Using cognitive work analysis and the strategies analysis diagram to understand variability in road user behaviour at intersections." Ergonomics no. 56 (5):764-780. doi: 10.1080/00140139.2013.768707. 
Cornelissen, Miranda, Paul M. Salmon, and Kristie L. Young. 2012. "Same but different? Understanding road user behaviour at intersections using cognitive work analysis." Theoretical Issues in Ergonomics Science no. 14 (6):592-615. doi: 10.1080/1463922x.2012.678282.

Creaser, Janet I., Michael E. Rakauskas, Nicholas J. Ward, Jason C. Laberge, and Max Donath. 2007. "Concept evaluation of intersection decision support (IDS) system interfaces to support drivers' gap acceptance decisions at rural stopcontrolled intersections." Transportation Research Part F: Traffic Psychology and Behaviour no. 10 (3):208-228. doi: 10.1016/j.trf.2006.10.004.

Edquist, Jessica, Karen Stephan, Eric Wigglesworth, and Michael Lenné. 2009. A literature review of human factors safety issues as Australian level crossings. Clayton, Australia: Monash University Accident Research Centre.

Endsley, Mica R. 1995. "Toward a Theory of Situation Awareness in Dynamic Systems." Human Factors: The Journal of the Human Factors and Ergonomics Society no. 37 (1):32-64. doi: 10.1518/001872095779049543.

Galanter, Cathryn A., and Vimla L. Patel. 2005. "Medical decision making: a selective review for child psychiatrists and psychologists." Journal of Child Psychology and Psychiatry no. 46 (7):675-689. doi: 10.1111/j.1469-7610.2005.01452.x.

Hoffman, Robert R., Beth Crandall, and Nigel Shadbolt. 1998. "Use of the critical decision method to elicit expert knowledge: A case study in the methodology of cognitive task analysis." Human Factors no. 40 (2):254-276.

Klein, G. A., R. Calderwood, and D. MacGregor. 1989. "Critical decision method for eliciting knowledge." Systems, Man and Cybernetics, IEEE Transactions on no. 19 (3):462-472. doi: 10.1109/21.31053. 
Larsson, Peter, Sidney W. A. Dekker, and Claes Tingvall. 2010. "The need for a systems theory approach to road safety." Safety Science no. 48 (9):1167-1174. doi: 10.1016/j.ssci.2009.10.006.

Lenné, Michael G., Vanessa Beanland, Paul M. Salmon, Ashleigh J. Filtness, and Neville A. Stanton. 2013. "Checking for trains: An on-road study of what drivers actually do at level crossings." In Rail Human Factors: Supporting reliability, safety and cost reduction, edited by N. Dadashi, A. Scott, J. R. Wilson and A. Mills, 53-59. London, UK: Taylor \& Francis.

Lobb, B., N. Harre, and N. Terry. 2003. "An evaluation of four types of railway pedestrian crossing safety intervention." Accident Analysis \& Prevention no. 35 (4):487-494.

Neisser, Ulric. 1976. Cognition and Reality: Principles and Implications of Cognitive Psychology. San Francisco, CA: Freeman.

O’Hare, David, Mark Wiggins, Anthony Williams, and William Wong. 1998. "Cognitive task analyses for decision centred design and training." Ergonomics no. 41 (11): 1698-1719.

Plant, Katherine L., and Neville A. Stanton. 2013a. "The explanatory power of Schema Theory: theoretical foundations and future applications in Ergonomics." Ergonomics no. 56 (1):1-15. doi: 10.1080/00140139.2012.736542. 2013b. "What is on your mind? Using the perceptual cycle model and critical decision method to understand the decision-making process in the cockpit." Ergonomics no. 56 (8):1232-1250. doi: 10.1080/00140139.2013.809480.

Read, Gemma J. M., Paul M. Salmon, and Michael G. Lenné. 2013. "Sounding the warning bells: The need for a systems approach to understanding behaviour at 
rail level crossings." Applied Ergonomics no. 44 (5):764-774. doi:

10.1016/j.apergo.2013.01.007.

Saccomanno, Frank F., Peter Young-Jin Park, and Liping Fu. 2007. "Estimating countermeasure effects for reducing collisions at highway-railway grade crossings." Accident Analysis \& Prevention no. 39 (2):406-416. doi: 10.1016/j.aap.2006.08.016.

Salmon, Paul M., Vanessa Beanland, Ashleigh J. Filtness, Michael G. Lenné, and Neville Stanton. 2013. "Waiting for warning: Driver situation awareness at rural rail level crossings." In Contemporary Ergonomics \& Human Factors 2013., edited by Martin Anderson, 403-410. Cambridge, UK: Taylor \& Francis.

Salmon, Paul, Michael Lenné, Vanessa Beanland, Ashleigh Filtness, Neville Stanton, and Gemma Read. 2014. "From the Bush to the Burbs: a comparison of driver situation awareness at rural and urban railway level crossings." In Proceedings of the 2014 Australasian Road Safety Research, Policing \& Education Conference, 1-10. Canberra, Australia: Australasian College of Road Safety.

Salmon, Paul M., Michael G. Lenné, Guy H. Walker, Neville A. Stanton, and Ashleigh Filtness. 2014. "Exploring schema-driven differences in situation awareness between road users: an on-road study of driver, cyclist and motorcyclist situation awareness." Ergonomics no. 57 (2):191-209. doi:

10.1080/00140139.2013.867077.

Salmon, Paul M., Gemma J. M. Read, Neville A. Stanton, and Michael G. Lenné. 2013. "The crash at Kerang: Investigating systemic and psychological factors leading to unintentional non-compliance at rail level crossings." Accident Analysis \& Prevention no. 50:1278-1288. doi: 10.1016/j.aap.2012.09.029. 
Salmon, Paul M., Neville A. Stanton, Michael G. Lenné, Daniel P. Jenkins, Laura Rafferty, and Guy H. Walker. 2011. Human Factors Methods and Accident Analysis: Practical Guidance and Case Study Applications. Aldershot, UK: Ashgate.

Salmon, Paul M., Kristie L. Young, and Miranda Cornelissen. 2013. "Compatible cognition amongst road users: The compatibility of driver, motorcyclist, and cyclist situation awareness." Safety Science no. 56:6-17. doi: 10.1016/j.ssci.2012.02.008.

Stanton, N. A., R. Stewart, D. Harris, R. J. Houghton, C. Baber, R. McMaster, P. Salmon, G. Hoyle, G. Walker, M. S. Young, M. Linsell, R. Dymott, and D. Green. 2006. "Distributed situation awareness in dynamic systems: theoretical development and application of an ergonomics methodology." Ergonomics no. 49 (12-13):1288-1311. doi: 10.1080/00140130600612762.

Stanton, Neville A., Paul M. Salmon, Guy H. Walker, and Daniel Jenkins. 2009a. "Genotype and phenotype schemata and their role in distributed situation awareness in collaborative systems." Theoretical Issues in Ergonomics Science no. 10 (1):43-68. doi: 10.1080/14639220802045199.

_. 2009b. "Genotype and phenotype schemata as models of situation awareness in dynamic command and control teams." International Journal of Industrial Ergonomics no. 39 (3):480-489. doi: 10.1016/j.ergon.2008.10.003.

Stanton, Neville A., Paul M. Salmon, Guy H. Walker, and Daniel P. Jenkins. 2010. "Is situation awareness all in the mind?" Theoretical Issues in Ergonomics Science no. 11 (1-2):29-40. doi: 10.1080/14639220903009938. 
Stanton, Neville A., and Guy H. Walker. 2011. "Exploring the psychological factors involved in the Ladbroke Grove rail accident." Accident Analysis \& Prevention no. 43 (3):1117-1127. doi: 10.1016/j.aap.2010.12.020.

Tey, Li-Sian, Luis Ferreira, and Angela Wallace. 2011. "Measuring driver responses at railway level crossings." Accident Analysis \& Prevention no. 43 (6):2134-2141. doi: 10.1016/j.aap.2011.06.003.

Walker, Guy H., Neville A. Stanton, Tara A. Kazi, Paul M. Salmon, and Daniel P. Jenkins. 2009. "Does advanced driver training improve situational awareness?" Applied Ergonomics no. 40 (4):678-687. doi: 10.1016/j.apergo.2008.06.002.

Walker, Guy H., Neville A. Stanton, and Paul M. Salmon. 2011. "Cognitive compatibility of motorcyclists and car drivers." Accident Analysis \& Prevention no. 43 (3):878-888. doi: 10.1016/j.aap.2010.11.008.

Wigglesworth, E. 1976. Report on human factors in road-rail crossing accidents. Melbourne, Australia: Ministry of Transport, Victoria.

Young, Kristie, Michael G. Lenné, Vanessa Beanland, Paul M. Salmon, and Neville A. Stanton. 2014. "Drivers' visual scanning and head check behavior on approach to urban rail level crossings." In Advances in Human Aspects of Transportation: Part 1, edited by N. Stanton, S. Landry, G. Di Bucchianico and A. Vallicelli, 482-490. Lexington, KY: AHFE.

Young, Kristie, Michael G. Lenné, Vanessa Beanland, Paul M. Salmon, and Neville A. Stanton. 2015. "Where do novice and experienced drivers direct their attention on approach to urban rail level crossings? " Accident Analysis \& Prevention no. $77: 1-11$ 


\title{
Variability in decision-making and critical cue use by different road users at rail level crossings
}

\author{
Vanessa Beanland, Michael G. Lenné, Paul M. Salmon, and Neville A. \\ Stanton
}

\section{Supplementary Materials}

These supplementary materials provide full results for the CDM probes: Assessment; Cue identification; Situation awareness; Information integration; Influencing factors; Decision-making; Mental models; Experience; and Conceptual. The key findings for each of these probes are also presented within the Results section of the manuscript itself.

\subsection{Assessment probe}

The assessment probe explored participants' assessment of the situation when they encountered the RLX. Participants responded by choosing pre-specified responses to the closed-ended question "What were the conditions at the time of this rail level crossing encounter?" Multiple responses were permitted, with an additional open-ended response box.

The most frequently experienced conditions were: heavy traffic (50\%); being the first to arrive at RLX (26\%); pedestrians near RLX (24\%); vehicles merging into my lane near RLX (19\%); needing to stop or turn after the RLX (16\%); having turned onto the road just before RLX (15\%); cyclists near RLX (11\%); and being in a hurry (11\%). Tables S1 and S2 show the relative prevalence of these conditions by road user group and decision made, respectively. It was rare for participants to be talking to a passenger or companion $(5 \%)$, talking on a phone $(2 \%)$, texting or looking up information on a 
phone $(1 \%)$ or using another portable device $(7 \%)$. It was also rare for participants to be positioned behind a large vehicle that obstructed their view of the RLX (4\%).

As shown in Table S1, some of the conditions experienced differed between road users. Drivers were less likely than other road users to be the first to arrive at the RLX. Compared to motorcyclists and cyclists, drivers and pedestrians were less likely to have to stop or turn either just before or just after the RLX. Compared to motorised road users (i.e., cars and motorcyclists), non-motorised road users (i.e., pedestrians and cyclists) were more likely to report seeing pedestrians and cyclists near the RLX, and were more likely to report being in a hurry.

Table S1. Most frequently reported conditions during RLX encounters, comparing road user groups

\begin{tabular}{|l|l|l|l|l|l|l|}
\hline \multirow{2}{*}{ Conditions } & Drivers & Motorcyclists & Cyclists & Pedestrians & \multicolumn{2}{|l|}{ Significance } \\
\cline { 5 - 8 } & & & & Wald $\chi^{2}$ & $p$ \\
\hline Heavy traffic & $57 \%^{\mathrm{a}}$ & $47 \%^{\mathrm{a}}$ & $42 \%^{\mathrm{a}}$ & - & 3.53 & .171 \\
\hline $\begin{array}{l}\text { I was first to arrive at } \\
\text { RLX }\end{array}$ & $13 \%^{\mathrm{a}}$ & $30 \%^{\mathrm{b}}$ & $32 \%^{\mathrm{b}}$ & $35 \%^{\mathrm{b}}$ & 12.05 & $.007^{* *}$ \\
\hline Pedestrians near RLX & $18 \%^{\mathrm{a}}$ & $14 \%^{\mathrm{a}}$ & $29 \%^{\mathrm{b}}$ & $32 \%^{\mathrm{b}}$ & 14.69 & $.002^{* *}$ \\
\hline $\begin{array}{l}\text { Vehicles were merging } \\
\text { into my lane near RLX }\end{array}$ & $15 \%^{\mathrm{a}}$ & $19 \%^{\mathrm{a}}$ & $26 \%^{\mathrm{a}}$ & - & 4.17 & .125 \\
\hline $\begin{array}{l}\text { I had to stop or turn after } \\
\text { the RLX }\end{array}$ & $10 \%^{\mathrm{a}}$ & $21 \%^{\mathrm{b}}$ & $24 \%^{\mathrm{b}}$ & $13 \%^{\mathrm{a}}$ & 9.59 & $.022^{*}$ \\
\hline $\begin{array}{l}\text { I turned onto the road just } \\
\text { before RLX }\end{array}$ & $16 \%^{\mathrm{a}}$ & $22 \%^{\mathrm{a}}$ & $19 \%^{\mathrm{a}}$ & $9 \%^{\mathrm{b}}$ & 9.63 & $.022^{*}$ \\
\hline Cyclists near RLX & $6 \%^{\mathrm{a}}$ & $4 \%^{\mathrm{a}}$ & $17 \%^{\mathrm{b}}$ & $16 \%^{\mathrm{b}}$ & 14.56 & $.002^{* *}$ \\
\hline I was in a hurry & $8 \%^{\mathrm{a}}$ & $1 \%^{\mathrm{a}}$ & $15 \%^{\mathrm{b}}$ & $17 \%^{\mathrm{b}}$ & 9.78 & $.021^{*}$ \\
\hline
\end{tabular}

Note. Groups with identical superscript letters (within each row) are not significantly different at $p<.05$. Multiple response options were permitted so columns many not sum to $100 \%$.

$* p<.05$

$*_{* * * *}^{* *} p<.01$ ${ }^{* * * *} p<.001$

Some conditions applied only to specific road user groups, and were therefore not compared between groups. These included: pedestrians or cyclists crossing in a group (17\%); walking or riding with a child (6\%); walking or riding with an animal 
$(<1 \%)$; or pedestrians not having other pedestrians nearby to influence their behaviour $(20 \%)$.

As shown in Table S2, three approach conditions showed a statistically significant association with the decision made at the RLX. Participants were less likely to cross before a train when in heavy traffic, but were more likely to cross before a train when they were first at the crossing or were in a hurry.

Table S2. Most frequently reported conditions during RLX encounters, by decision made

\begin{tabular}{|c|c|c|c|c|c|c|}
\hline \multirow{2}{*}{ Conditions } & \multirow{2}{*}{$\begin{array}{l}\text { Crossed } \\
\text { after train }\end{array}$} & \multirow{2}{*}{$\begin{array}{l}\text { Crossed } \\
\text { before } \\
\text { train }\end{array}$} & \multicolumn{2}{|c|}{ Significance } & \multicolumn{2}{|c|}{$\begin{array}{l}\text { Odds Ratio } \\
(\text { OR })\end{array}$} \\
\hline & & & $\begin{array}{l}\text { Wald } \\
\chi^{2}\end{array}$ & & OR & $\begin{array}{l}95 \% \mathrm{CI} \\
\text { OR }\end{array}$ \\
\hline Heavy traffic & $52 \%$ & $8 \%$ & 5.50 & $019^{*}$ & 0.09 & $\begin{array}{l}{[0.01,} \\
0.67]\end{array}$ \\
\hline $\begin{array}{l}\text { I was first to arrive at } \\
\text { RLX }\end{array}$ & $22 \%$ & & 15.95 & $<.001^{* * *}$ & 4.17 & $\begin{array}{l}{[2.07} \\
8.40]\end{array}$ \\
\hline Pedestrians near RLX & $24 \%$ & $20 \%$ & 1.68 & .195 & 0.58 & $\begin{array}{l}{[0.25} \\
1.33]\end{array}$ \\
\hline $\begin{array}{l}\text { Vehicles were merging } \\
\text { into my lane near RLX }\end{array}$ & $20 \%$ & $8 \%$ & 1.36 & .244 & 0.29 & $\begin{array}{l}{[0.04,} \\
2.32]\end{array}$ \\
\hline $\begin{array}{l}\text { I had to stop or turn after } \\
\text { the RLX }\end{array}$ & $16 \%$ & $18 \%$ & 0.21 & .647 & 1.23 & $\begin{array}{l}{[0.50,} \\
3.02]\end{array}$ \\
\hline $\begin{array}{l}\text { I turned onto the road } \\
\text { just before RLX }\end{array}$ & $15 \%$ & $20 \%$ & 2.68 & .101 & 2.10 & $\begin{array}{l}{[0.87} \\
5.08]\end{array}$ \\
\hline Cyclists near RLX & $11 \%$ & $5 \%$ & 2.89 & .089 & 0.28 & $\begin{array}{l}{[0.06,} \\
1.22]\end{array}$ \\
\hline I was in a hurry & $10 \%$ & $23 \%$ & 2.72 & .099 & 2.06 & $\begin{array}{l}{[0.87} \\
4.86]\end{array}$ \\
\hline
\end{tabular}

Note. Multiple response options were permitted so columns many not sum to $100 \%$.

$* p<.05$

${ }^{* * *} p<.01$

${ }^{* * *} p<.001$ 


\subsection{Cue identification}

The cue identification probe asked participants to nominate the cue that first alerted them to the presence of the train and/or the activated warnings. Participants responded by choosing one option only, from a pre-specified list of possible cues.

The most frequently reported cues that first alerted participants to the presence of the train or activated warnings were flashing lights (39\%), bells (25\%), and seeing a train $(10 \%)$. All other potential cues were reported by fewer than $10 \%$ of respondents. This included: behaviour of other road vehicles (8\%); boom barriers at the RLX (8\%); hearing a train (3\%); signs at the RLX (3\%); advisory signs before the RLX (2\%); behaviour of pedestrians or cyclists near the RLX (2\%); road markings leading up to the RLX (1\%); and pedestrian gates or barriers (1\%).

Use of both flashing lights, $\chi^{2}(3)=43.38, p<.001$, and bells, $\chi^{2}(3)=51.08, p<$ .001 , as cues differed significantly between road user groups, but seeing a train did not. Compared to drivers, cyclists (OR 0.43, $\left.\mathrm{CI}_{95 \%}[0.24,0.76]\right)$ and pedestrians (OR 0.22, $\left.\mathrm{CI}_{95 \%}[0.12,0.38]\right)$ were less likely to use flashing lights as a cue, but were more likely to use bells (cyclists: OR 12.5, $\mathrm{CI}_{95 \%}[5.20,3.0]$; pedestrians: OR 12.2, $\mathrm{CI}_{95 \%}$ [5.3, 28.4]). Motorcyclists did not differ from drivers.

Participants who crossed before the train were more likely to report seeing a train as their first cue, $\chi^{2}(1)=7.89, p=.005$, OR 3.23, $\mathrm{CI}_{95 \%}[1.43,7.31]$.

\subsection{Situation awareness}

The situation awareness probe explored participants' situation awareness at the time when they made the decision to stop or proceed through the RLX. Participants responded by choosing pre-specified responses to the closed-ended question "What information did you use when you made your decision to stop or proceed at this level 
crossing?" Multiple responses were permitted, with an additional open-ended response box.

Participants reported using an average of 3-4 distinct information elements to make their decision. Number of information elements used did not vary between road users, $F(3,433)=0.24, p=.865$, or decision made, $F(1,433)=0.23, p=.630$. The most frequently reported information elements were: lights were flashing (68\%); booms were down/descending (64\%); bells were ringing (58\%); behaviour of vehicles (31\%); could see a train (26\%); signs saying "Railway Crossing” (22\%); traffic lights (16\%); could hear a train $(15 \%)$; and could not see a train $(11 \%)$.

Information elements that were reported as being infrequently used included: advance warning signs (10\%); how long the light had been on/booms had been down (9\%); pedestrian gates were closed/closing (8\%); behaviour of pedestrians or cyclists at the crossing (8\%); sight distance along the tracks (7\%); could not hear a train $(7 \%)$; painted road markings (6\%); how long the gates had been closed (4\%); booms were up/ascending (3\%); lights were not flashing (3\%); bells were not ringing (2\%); space available on other side of RLX (2\%); and pedestrian gates were open/opening (1\%).

Situation awareness differed between road users, as shown in Table S3. Compared to drivers, motorcyclists were more likely to use flashing lights (OR 2.8, $\left.\mathrm{CI}_{95 \%}[1.2,6.6]\right)$ and not seeing a train $\left(\mathrm{OR} 2.8, \mathrm{CI}_{95 \%}[1.2,6.8]\right)$, but were less likely to use traffic lights (OR 0.4, $\left.\mathrm{CI}_{95 \%}[0.2,0.7]\right)$. Whereas motorised road users relied on visual information, non-motorised road users relied more on auditory information. Cyclists were more likely than drivers to use hearing a train (OR 6.3, $\left.\mathrm{CI}_{95 \%}[2.5,15.5]\right)$ and bells (OR 1.9, $\left.\mathrm{CI}_{95 \%}[1.1,3.3]\right)$, but were less likely to use flashing lights, (OR 0.4, $\left.\mathrm{CI}_{95 \%}[0.2,0.7]\right)$ and behaviour of vehicles (OR 0.4, $\left.\mathrm{CI}_{95 \%}[0.2,0.8]\right)$. Similarly, compared to drivers, pedestrians more likely to use hearing a train (OR 6.8, $\mathrm{CI}_{95 \%}$ [2.9, 
16.2]) and bells (OR 2.7, $\left.\mathrm{CI}_{95 \%}[1.6,4.6]\right)$, but were less likely to use traffic lights (OR

0.1, $\left.\mathrm{CI}_{95 \%}[0.03,0.2]\right)$, behaviour of vehicles (OR 0.3, $\left.\mathrm{CI}_{95 \%}[0.1,0.5]\right)$ or flashing lights

(OR 0.4, $\left.\mathrm{CI}_{95 \%}[0.2,0.6]\right)$.

Table S3. Information elements most frequently used during RLX encounters, by road user group.

\begin{tabular}{|l|l|l|l|l|l|l|}
\hline \multirow{2}{*}{ Information element } & Drivers & \multirow{2}{*}{ Motorcyclists } & \multirow{2}{*}{ Cyclists } & \multirow{2}{*}{ Pedestrians } & \multicolumn{2}{|l|}{ Significance } \\
\cline { 5 - 8 } & & & & & Wald $\chi^{2}$ & $p$ \\
\hline Lights were flashing & $79 \%^{\mathrm{a}}$ & $91 \%^{\mathrm{b}}$ & $57 \%^{\mathrm{c}}$ & $51 \%^{\mathrm{c}}$ & 35.98 & $<.001^{* * *}$ \\
\hline Booms down/descending & $73 \%^{\mathrm{a}}$ & $69 \%^{\mathrm{a}}$ & $58 \%^{\mathrm{a}}$ & $55 \%^{\mathrm{a}}$ & 5.37 & .146 \\
\hline Bells ringing & $47 \%^{\mathrm{a}}$ & $59 \%^{\mathrm{ab}}$ & $61 \%^{\mathrm{b}}$ & $66 \%^{\mathrm{b}}$ & 14.72 & $.002^{* *}$ \\
\hline Behaviour of vehicles & $42 \%^{\mathrm{a}}$ & $48 \%^{\mathrm{a}}$ & $24 \%^{\mathrm{b}}$ & $14 \%^{\mathrm{b}}$ & 30.79 & $<.001^{* * *}$ \\
\hline Traffic lights & $30 \%^{\mathrm{a}}$ & $13 \%^{\mathrm{b}}$ & $20 \%^{\mathrm{a}}$ & $3 \%^{\mathrm{b}}$ & 24.52 & $<.001^{* * *}$ \\
\hline $\begin{array}{l}\text { Signs saying "Railway } \\
\text { Crossing" }\end{array}$ & $28 \%^{\mathrm{a}}$ & $22 \%^{\mathrm{a}}$ & $14 \%^{\mathrm{a}}$ & $21 \%^{\mathrm{a}}$ & 4.77 & .189 \\
\hline Could see a train & $24 \%^{\mathrm{ab}}$ & $16 \%^{\mathrm{a}}$ & $21 \%^{\mathrm{a}}$ & $37 \%^{\mathrm{b}}$ & 10.82 & $.013^{*}$ \\
\hline Could not see a train & $7 \%^{\mathrm{a}}$ & $17 \%^{\mathrm{b}}$ & $15 \%^{\mathrm{ab}}$ & $9 \%^{\mathrm{a}}$ & 8.27 & $.041^{*}$ \\
\hline Could hear a train & $5 \%^{\mathrm{a}}$ & $2 \%^{\mathrm{a}}$ & $26 \%^{\mathrm{b}}$ & $27 \%^{\mathrm{b}}$ & 31.79 & $<.001^{* * *}$ \\
\hline
\end{tabular}

Note. Groups with identical superscript letters (within each row) are not significantly different at $p<.05$.

Multiple response options were permitted so columns many not sum to $100 \% .{ }^{*} p<.05$

${ }^{* *} p<.01$

$*^{* * *} p<.001$

Use of four information elements also varied with decision made, as shown in

Table S4. Participants who crossed before the train were significantly less likely to use

booms descending, behaviour of vehicles, lights flashing, and bells ringing as

information sources. Use of the other information elements did not differ between road

users who crossed before vs. after the train. 
Table S4. Information elements most frequently used during RLX encounters, by decision made.

\begin{tabular}{|c|c|c|c|c|c|c|}
\hline \multirow{2}{*}{ Information element } & \multirow{2}{*}{$\begin{array}{l}\text { Crossed } \\
\text { after train }\end{array}$} & \multirow{2}{*}{$\begin{array}{l}\text { Crossed } \\
\text { before } \\
\text { train }\end{array}$} & \multicolumn{2}{|c|}{ Significance } & \multicolumn{2}{|c|}{$\begin{array}{l}\text { Odds Ratio } \\
\text { (OR) }\end{array}$} \\
\hline & & & $\begin{array}{l}\text { Wald } \\
\chi^{2}\end{array}$ & $p$ & OR & $\begin{array}{l}95 \% \mathrm{CI} \\
\text { OR }\end{array}$ \\
\hline Lights were flashing & $73 \%$ & $25 \%$ & 19.75 & $<.001^{* * *}$ & 0.16 & $\begin{array}{l}{[0.07} \\
0.36]\end{array}$ \\
\hline Booms down/descending & $68 \%$ & $15 \%$ & 26.38 & $<.001^{* * *}$ & 0.09 & $\begin{array}{l}{[0.04} \\
0.23]\end{array}$ \\
\hline Bells ringing & $60 \%$ & $40 \%$ & 10.39 & $.001^{*}$ & 0.32 & $\begin{array}{l}{[0.16} \\
0.64]\end{array}$ \\
\hline Behaviour of vehicles & $33 \%$ & $5 \%$ & 5.92 & $.015^{*}$ & 0.16 & $\begin{array}{l}{[0.04} \\
0.70]\end{array}$ \\
\hline Could see a train & $25 \%$ & $40 \%$ & & .197 & 1.59 & $\begin{array}{l}0.79 \\
3.21]\end{array}$ \\
\hline $\begin{array}{l}\text { Signs saying "Railway } \\
\text { Crossing" }\end{array}$ & $23 \%$ & $10 \%$ & & .084 & 0.39 & $\begin{array}{l}{[0.13,} \\
1.14]\end{array}$ \\
\hline Traffic lights & $18 \%$ & $0 \%$ & - & -- & -- & -- \\
\hline Could hear a train & $15 \%$ & & 0.71 & .400 & 0.68 & $\begin{array}{l}{[0.28,} \\
1.67]\end{array}$ \\
\hline Could not see a train & $11 \%$ & $15 \%$ & 1.06 & .304 & 1.66 & $\begin{array}{l}{[0.63,} \\
4.40]\end{array}$ \\
\hline
\end{tabular}

Note. Multiple response options were permitted so columns many not sum to $100 \%$.

${ }_{* *}^{*}<.05$

${ }_{* * *}^{* *}<.01$

$p<.001$

\subsection{Information Integration}

The information integration probe was related to the situation awareness probe,

in that it also examined information use at the RLX, but differed in that it explicitly sought the single most important piece of information that informed the participant's decision. Participants responded by choosing one response from a set of pre-specified options. 
The most important information sources reportedly used at RLXs included: lights flashing (24\%); boom barriers down/descending (21\%); bells ringing (17\%); and seeing a train $(10 \%)$.

The relative importance of booms descending did not differ significantly between groups. Flashing lights were more important to motorised vs. non-motorised road users, $\chi^{2}(1)=19.36, p<.001$, OR 2.9, $\mathrm{CI}_{95 \%}[1.8,4.7]$, and among motorised road users, flashing lights were more important to motorcyclists vs. drivers, $\chi^{2}(1)=7.69, p=$ $.006, \mathrm{OR} 2.3, \mathrm{CI}_{95 \%}[1.3,4.0]$. Conversely, non-motorised road users were more likely than motorists to rely on ringing bells, $\chi^{2}(1)=33.47, p<.001, \mathrm{OR}_{7.0}, \mathrm{Cl}_{95 \%}[3.6,13.5]$, and pedestrians were more likely than other road users to rely on seeing a train, $\chi^{2}(1)=$ $13.83, p<.001$, OR 3.4, $\mathrm{CI}_{95 \%}[1.8,6.4]$.

Only flashing lights showed differences according to decision made: participants who crossed before the train were less likely use flashing lights as their primary information source, $\chi^{2}(1)=5.20, p=.023$, OR $0.1, \mathrm{CI}_{95 \%}[0.01,0.7]$.

\subsection{Influencing Factors}

The influencing factors probe used two questions to identify the factors that influenced participants' decision making at the RLX. First participants responded to the question "What factors influenced your decision to stop or proceed at this level crossing?" by choosing the relevant factors from a list of pre-specified options. Multiple options were allowed to this first question, since it sought to identify all of the factors that influenced participants. Following this, the second question asked participants to nominate the single most important factor that influenced their decision to stop or proceed. The response options were the same as for the previous question, except that only one response could be selected. 


\subsubsection{Multiple factors that influenced decision-making}

The most frequently reported factors influencing participants' decisions at RLXs were: presence or operation of boom barriers (55\%); presence or operation of bells (46\%); prior experience at this RLX (44\%); presence or operation of flashing lights (41\%); seeing a train (29\%); behaviour of vehicles (27\%); prior experience at other RLXs (26\%); traffic lights (15\%); hearing a train (14\%); presence of signs saying "Railway Crossing" (14\%); presence or operation of pedestrian gates (11\%).

As shown in Table S5, "prior experience at this RLX" was the only one among that 11 most commonly-reported influencing factors that did not differ between road users. There was strong differentiation between motorised and non-motorised road users. Motorcyclists were similar to drivers, albeit more likely to be influenced by bells (OR 2.3, $\left.\mathrm{CI}_{95 \%}[1.3,4.1]\right)$ and prior experience at other RLXs (OR 3.6, $\left.\mathrm{CI}_{95 \%}[1.9,6.6]\right)$. Cyclists more likely than drivers to be influenced by auditory factors, namely bells (OR 1.9, $\left.\mathrm{CI}_{95 \%}[1.1,3.4]\right)$ and hearing a train (OR 6.0, $\left.\mathrm{CI}_{95 \%}[2.1,17.0]\right)$; but were less likely to be influenced by visual factors including behaviour of vehicles (OR 0.2, $\mathrm{CI}_{95 \%}[0.1$, 0.4]), signs (OR 0.2, $\left.\mathrm{CI}_{95 \%}[0.1,0.6]\right)$, and flashing lights (OR 0.4, $\mathrm{CI}_{95 \%}[0.3,0.8]$ ). Pedestrians were less likely than drivers to be influenced by behaviour of vehicles (OR 0.2, $\left.\mathrm{CI}_{95 \%}[0.1,0.4]\right)$, booms (OR 0.2, $\left.\mathrm{CI}_{95 \%}[0.1,0.4]\right)$, traffic lights (OR 0.2, $\mathrm{CI}_{95 \%}$ $[0.1,0.4]$ ), flashing lights (OR 0.3, $\left.\mathrm{CI}_{95 \%}[0.2,0.6]\right)$, and signs (OR 0.4, $\mathrm{CI}_{95 \%}[0.2$, 0.8]). However, pedestrians were more likely than drivers to be influenced by the operation of pedestrian gates (OR 27.2, $\left.\mathrm{CI}_{95 \%}[6.4,116.2]\right)$; hearing a train (OR 10.0,

$\left.\mathrm{CI}_{95 \%}[3.7,26.5]\right)$; and seeing a train (OR 3.0, $\left.\mathrm{CI}_{95 \%}[1.7,5.1]\right)$. 
Table S5. Most frequently reported factors influencing decisions at RLXs, by road user group.

\begin{tabular}{|l|l|l|l|l|l|l|}
\hline \multirow{2}{*}{ Influencing factor } & \multirow{2}{*}{ Drivers } & Motorcyclists & \multirow{2}{*}{ Cyclists } & Pedestrians & \multicolumn{2}{|l|}{ Significance } \\
\cline { 5 - 8 } & & & & Wald $\chi^{2}$ & $p$ \\
\hline Boom barriers & $70 \%^{\mathrm{a}}$ & $69 \%^{\mathrm{a}}$ & $55 \%^{\mathrm{a}}$ & $33 \%^{\mathrm{b}}$ & 33.86 & $<.001^{* * *}$ \\
\hline Bells & $39 \%^{\mathrm{a}}$ & $59 \%^{\mathrm{b}}$ & $54 \%^{\mathrm{b}}$ & $39 \%^{\mathrm{a}}$ & 12.51 & $.006^{* *}$ \\
\hline Experience at this RLX & $37 \%^{\mathrm{a}}$ & $50 \%^{\mathrm{a}}$ & $46 \%^{\mathrm{a}}$ & $45 \%^{\mathrm{a}}$ & 3.49 & .323 \\
\hline Flashing lights & $53 \%^{\mathrm{a}}$ & $58 \%^{\mathrm{a}}$ & $33 \%^{\mathrm{b}}$ & $25 \%^{\mathrm{b}}$ & 28.19 & $<.001^{* * *}$ \\
\hline Seeing a train & $22 \%^{\mathrm{a}}$ & $17 \%^{\mathrm{a}}$ & $25 \%^{\mathrm{a}}$ & $46 \%^{\mathrm{b}}$ & 25.32 & $<.001^{* * *}$ \\
\hline Behaviour of vehicles & $44 \%^{\mathrm{a}}$ & $37 \%^{\mathrm{a}}$ & $14 \%^{\mathrm{b}}$ & $12 \%^{\mathrm{b}}$ & 37.07 & $<.001^{* * *}$ \\
\hline Experience at other RLXs & $18 \%^{\mathrm{a}}$ & $43 \%^{\mathrm{b}}$ & $28 \%^{\mathrm{a}}$ & $21 \%^{\mathrm{a}}$ & 18.74 & $<.001^{* * *}$ \\
\hline Traffic lights & $24 \%^{\mathrm{a}}$ & $17 \%^{\mathrm{a}}$ & $18 \%^{\mathrm{a}}$ & $4 \%^{\mathrm{b}}$ & 14.69 & $.002^{* *}$ \\
\hline Hearing a train & $4 \%^{\mathrm{a}}$ & $6 \%^{\mathrm{a}}$ & $19 \%^{\mathrm{b}}$ & $27 \%^{\mathrm{b}}$ & 29.93 & $<.001^{* * *}$ \\
\hline $\begin{array}{l}\text { Signs saying "Railway } \\
\text { Crossing" }\end{array}$ & $24 \%^{\mathrm{a}}$ & $13 \%^{\mathrm{ab}}$ & $6 \%^{\mathrm{b}}$ & $10 \%^{\mathrm{b}}$ & 13.69 & $.003^{* *}$ \\
\hline Pedestrian gates & $2 \%^{\mathrm{a}}$ & $1 \% \%^{\mathrm{a}}$ & $6 \%^{\mathrm{a}}$ & $29 \%^{\mathrm{b}}$ & 40.17 & $<.001^{* * *}$ \\
\hline
\end{tabular}

Note. Groups with identical superscript letters (within each row) are not significantly different at $p<.05$. Multiple response options were permitted so columns many not sum to $100 \%$.

* $p<.05$

${ }_{* * *}^{* *} p<.01$

$p<.001$

As shown in Table S6, four factors showed differential influence depending on the decision made. Participants who crossed before a train were less likely to be influenced by behaviour of vehicles ( $\left.\mathrm{OR} 0.06, \mathrm{CI}_{95 \%}[0.01,0.46]\right)$, the presence or operation of flashing lights (OR $\left.0.18, \mathrm{CI}_{95 \%}[0.07,0.47]\right)$, the presence or operation of boom barriers $\left(\mathrm{OR} 0.24, \mathrm{CI}_{95 \%}[0.11,0.51]\right)$ and the presence or operation of bells (OR $\left.0.42, \mathrm{CI}_{95 \%}[0.20,0.89]\right)$. 
Table S6. Most frequently reported factors influencing decisions at RLXs, by decision made.

\begin{tabular}{|l|l|l|l|l|}
\hline \multirow{2}{*}{ Information element } & \multirow{2}{*}{$\begin{array}{l}\text { Crossed after } \\
\text { train }\end{array}$} & \multirow{2}{*}{$\begin{array}{l}\text { Crossed before } \\
\text { train }\end{array}$} & \multicolumn{2}{|l|}{ Significance } \\
\cline { 4 - 6 } & & & $\chi^{2}$ & $p$ \\
\hline Boom barriers & $58 \%$ & $25 \%$ & 14.16 & $<.001^{* * *}$ \\
\hline Bells & $48 \%$ & $28 \%$ & 5.65 & $.017^{*}$ \\
\hline Experience at this RLX & $43 \%$ & $53 \%$ & 1.28 & .258 \\
\hline Flashing lights & $44 \%$ & $13 \%$ & 12.26 & $<.001^{* * *}$ \\
\hline Seeing a train & $28 \%$ & $40 \%$ & 2.41 & .120 \\
\hline Behaviour of vehicles & $29 \%$ & $3 \%$ & 7.43 & $.006^{* * *}$ \\
\hline Experience at other RLXs & $26 \%$ & $20 \%$ & 0.72 & .395 \\
\hline Traffic lights & $17 \%$ & $0 \%$ & 0.00 & .997 \\
\hline Hearing a train & $14 \%$ & $15 \%$ & 0.02 & .892 \\
\hline Signs saying "Railway Crossing" & $15 \%$ & $5 \%$ & 2.58 & .108 \\
\hline Pedestrian gates & $10 \%$ & $18 \%$ & 1.93 & .165 \\
\hline
\end{tabular}

Note. Multiple response options were permitted so columns many not sum to $100 \%$.

${ }^{*} p<.05$

$* * 0.01$

$p<.001$

\subsubsection{Single most important factor influencing decision-making}

When asked to specify the most important factor that influenced their decision, participants nominated: presence or operation of boom barriers (21\%); presence or operation of flashing lights (14\%); seeing a train (12\%); and prior experience at this RLX (11\%). The most important influencing factors did not vary according to decision made, but did vary between road user groups.

The importance of prior experience at the RLX was equivalent across groups, but relative importance of booms, $\chi^{2}(3)=19.48, p<.001$, flashing lights, $\chi^{2}(3)=30.62$, $p<.001$, and seeing a train, $\chi^{2}(3)=20.23, p<.001$, varied between groups. Pedestrians showed the greatest differentiation: compared to drivers, they were more likely to be influenced by seeing a train (OR $\left.2.9, \mathrm{CI}_{95 \%}[1.4,5.9]\right)$ and less likely to be influenced by booms (OR 0.2, $\left.\mathrm{CI}_{95 \%}[0.1,0.4]\right)$. Motorcyclists were more likely than drivers to be 
influenced by flashing lights (OR 2.3, $\left.\mathrm{CI}_{95 \%}[1.2,4.4]\right)$, whereas cyclists were less likely to be influenced by flashing lights (OR 0.4, $\left.\mathrm{CI}_{95 \%}[0.1,0.9]\right)$.

\subsection{Decision-making}

The decision-making probe asked participants to indicate how much time pressure was involved in making their decision to stop or proceed at the RLX: none, a little bit, a moderate amount, or a lot. Nearly three-quarters of the encounters (73\%) involved participants feeling no time pressure, so time pressure was analysed as a dichotomous variable (none vs. some). Time pressure was associated with both decision made, $\chi^{2}(1)=16.08, p<.001$, and road user group, $\chi^{2}(3)=18.18, p<.001$. Participants were more likely to report time pressure if they crossed before the train (OR 4.3, $\mathrm{CI}_{95 \%}$ $[2.1,8.9])$ or were pedestrians (OR 3.0, $\left.\mathrm{CI}_{95 \%}[1.7,5.4]\right)$.

\subsection{Mental Models}

The mental models probe explored whether participants used mental models to guide their decision-making. Participants responded to the question "Did you think about the potential consequences of your decision to stop or proceed before you made it?" If participants indicated that they did not consider the consequences before deciding on a course of action, they were required to indicate why (i.e., whether they made an automatic, unthinking decision, or whether there was too much time pressure so they did not have time to think about consequences). Most participants (87\%) reported they did not consider potential consequences of their decision before they made it.

Considering consequences was significantly associated with both the decision made, $\chi^{2}(1)=10.37, p=.001$, and road user group, $\chi^{2}(3)=16.80, p=.001$. Participants who crossed before the train were more likely to consider potential consequences of their decision, compared to those who crossed after (OR 3.5, $\left.\mathrm{CI}_{95 \%}[1.6,7.4]\right)$. 
Compared to drivers, both motorcyclists (OR 5.5, $\left.\mathrm{CI}_{95 \%}[1.7,17.5]\right)$ and pedestrians (OR 7.7, $\mathrm{CI}_{95 \%}[2.6,22.9]$ ), but not cyclists, were more likely to consider decision consequences. Among participants who failed to consider consequences, most (97\%) said that it was an automatic response but 3\% reported that they didn't have time to think.

\subsection{Experience}

Participants reported drawing on several sources of knowledge and experience to make their decision, including knowledge and experience of: RLXs in general (62\%); this particular RLX (55\%); road rules (46\%); road conditions (26\%); reliability of RLX warnings in general (25\%); acceleration or braking capabilities $(25 \%)$; reliability of warnings at this RLX (24\%); rail accidents or near misses (22\%); train speeds (20\%); train behaviour (18\%); and vehicle size $(17 \%)$.

Several knowledge sources differed between road users, as shown in Table S7. Motorcyclists showed several differences from drivers, being marginally less likely to use road rules (OR 0.6, $\left.\mathrm{CI}_{95 \%}[0.3,0.99]\right)$, but more likely to use knowledge of train speeds (OR 5.8, $\left.\mathrm{CI}_{95 \%}[2.4,14.5]\right)$, their acceleration and braking capabilities (OR 2.8, $\left.\mathrm{CI}_{95 \%}[1.4,5.3]\right)$ and the road surface (OR 2.9, $\left.\mathrm{CI}_{95 \%}[1.6,5.3]\right)$. Pedestrians were less likely than drivers to use road rules (OR $\left.0.2, \mathrm{CI}_{95 \%}[0.1,0.3]\right)$, but more likely to use knowledge of train speeds (OR 13.9, $\mathrm{CI}_{95 \%}[6.0,32.4]$ ). Compared to drivers, cyclists were more likely to draw on knowledge or experience of rail accidents and near misses (OR 2.8, $\left.\mathrm{CI}_{95 \%}[1.5,5.4]\right)$. 
Table S7. Previous experience or knowledge used to make decisions at RLXs, by road user group.

\begin{tabular}{|l|l|l|l|l|l|l|}
\hline \multirow{2}{*}{ Knowledge about... } & Drivers & Motorcyclists & Cyclists & Pedestrians & \multicolumn{2}{|l|}{ Significance } \\
\cline { 5 - 8 } & & & & Wald $\chi^{2}$ & $p$ \\
\hline RLXs in general & $64 \%^{\mathrm{ab}}$ & $70 \%^{\mathrm{a}}$ & $68 \%^{\mathrm{a}}$ & $50 \%^{\mathrm{b}}$ & 8.20 & $.042^{*}$ \\
\hline This particular RLX & $45 \%^{\mathrm{a}}$ & $58 \%^{\mathrm{a}}$ & $58 \%^{\mathrm{a}}$ & $60 \%^{\mathrm{a}}$ & 5.58 & .134 \\
\hline Road rules & $66 \%^{\mathrm{a}}$ & $51 \%^{\mathrm{b}}$ & $51 \%^{\mathrm{ab}}$ & $20 \%^{\mathrm{c}}$ & 43.64 & $<.001^{* * *}$ \\
\hline Road surface condition & $20 \%^{\mathrm{a}}$ & $42 \%^{\mathrm{b}}$ & $24 \%^{\mathrm{a}}$ & $24 \%^{\mathrm{a}}$ & 14.13 & $.003^{* *}$ \\
\hline $\begin{array}{l}\text { Acceleration or braking } \\
\text { capabilities }\end{array}$ & $15 \%^{\mathrm{a}}$ & $34 \%^{\mathrm{b}}$ & $22 \%^{\mathrm{ab}}$ & $30 \%^{\mathrm{ab}}$ & 9.51 & $.023^{*}$ \\
\hline $\begin{array}{l}\text { Reliability of warnings at } \\
\text { RLXs in general }\end{array}$ & $29 \%^{\mathrm{a}}$ & $23 \%^{\mathrm{a}}$ & $21 \%^{\mathrm{a}}$ & $26 \%^{\mathrm{a}}$ & 1.96 & .582 \\
\hline $\begin{array}{l}\text { Reliability of warnings at } \\
\text { this particular RLX }\end{array}$ & $16 \%^{\mathrm{a}}$ & $30 \%^{\mathrm{a}}$ & $28 \%^{\mathrm{a}}$ & $25 \%^{\mathrm{a}}$ & 6.86 & .077 \\
\hline $\begin{array}{l}\text { Rail accidents or near } \\
\text { misses }\end{array}$ & $17 \%^{\mathrm{a}}$ & $21 \%^{\mathrm{a}}$ & $35 \%^{\mathrm{b}}$ & $19 \%^{\mathrm{a}}$ & 11.26 & $.010^{*}$ \\
\hline Train speeds & & & $7 \%^{\mathrm{a}}$ & $40 \%^{\mathrm{b}}$ & 53.52 & $<.001^{* * *}$ \\
\hline Train behaviour & $14 \%^{\mathrm{a}}$ & $20 \%^{\mathrm{a}}$ & $18 \%^{\mathrm{a}}$ & $20 \%^{\mathrm{a}}$ & 1.56 & .670 \\
\hline Vehicle size or length & $13 \%^{\mathrm{a}}$ & $23 \%^{\mathrm{a}}$ & $16 \%^{\mathrm{a}}$ & - & 3.90 & .143 \\
\hline
\end{tabular}

Note. Groups with identical superscript letters (within each row) are not significantly different at $\mathrm{p}<.05$.

Multiple response options were permitted so columns many not sum to $100 \%$.

${ }^{*} p<.05$

${ }_{* * *}^{* *} p<.01$

${ }^{* * *} p<.001$

Four knowledge sources showed differential influence depending on the

decision made at the RLX, as shown in Table S8. Participants who crossed before train were more likely to use knowledge of their acceleration or braking capabilities (OR 3.93, $\left.\mathrm{CI}_{95 \%}[2.02,7.64]\right)$ and this particular RLX (OR 2.33, CI95\% [1.13, 4.79]), but were less likely to use knowledge of road rules (OR 0.12, $\mathrm{CI}_{95 \%}[0.04,0.33]$ ) or RLXs in general (OR 0.0.38, $\left.\mathrm{CI}_{95 \%}[0.19,0.73]\right)$. 
Table S8. Previous experience or knowledge used to make decisions at RLXs, by decision made.

\begin{tabular}{|l|l|l|l|l|}
\hline \multirow{2}{*}{ Knowledge about... } & \multirow{2}{*}{$\begin{array}{l}\text { Crossed after } \\
\text { train }\end{array}$} & \multirow{2}{*}{$\begin{array}{l}\text { Crossed before } \\
\text { train }\end{array}$} & \multicolumn{2}{|l|}{ Significance } \\
\cline { 3 - 5 } & $64 \%$ & $40 \%$ & $\chi^{2}$ & $p$ \\
\hline RLXs in general & $53 \%$ & $73 \%$ & 8.25 & $.004^{* *}$ \\
\hline This particular RLX & $49 \%$ & $10 \%$ & 5.27 & $.022^{*}$ \\
\hline Road rules & $26 \%$ & $30 \%$ & 16.25 & $<.001^{* * *}$ \\
\hline Road condition & $22 \%$ & $53 \%$ & 0.35 & .554 \\
\hline Acceleration or braking capabilities & $25 \%$ & $28 \%$ & 16.32 & $<.001^{* * *}$ \\
\hline $\begin{array}{l}\text { Reliability of warnings at RLXs in } \\
\text { general }\end{array}$ & & & 0.10 & .749 \\
\hline $\begin{array}{l}\text { Reliability of warnings at this particular } \\
\text { RLX }\end{array}$ & $23 \%$ & $35 \%$ & 2.97 & .085 \\
\hline Rail accidents or near misses & $23 \%$ & $10 \%$ & 3.33 & .068 \\
\hline Train speeds & $21 \%$ & $18 \%$ & 0.23 & .633 \\
\hline Train behaviour & $17 \%$ & $28 \%$ & 2.83 & .092 \\
\hline Vehicle size or length & $16 \%$ & $31 \%$ & 1.88 & .170 \\
\hline
\end{tabular}

Note. Multiple response options were permitted so columns many not sum to $100 \%$.

${ }^{*} p<.05$

${ }_{* * *}^{* *} p<.01$

${ }^{* * *} p<.001$

\subsection{Conceptual}

For $20 \%$ of encounters, participants described situations in which their decision would have turned out differently. Participants who crossed before the train were more likely to describe alternative situations, $\chi^{2}(1)=30.62, p<.001$, OR 3.1, $\mathrm{CI}_{95 \%}[1.5,6.4]$. Tendency to describe alternative situations also differed between road users, $\chi^{2}(3)=$ 13.86, $p=.003$. Compared to drivers, motorcyclists (OR 3.0, $\left.\mathrm{CI}_{95 \%}[1.4,6.5]\right)$ and cyclists (OR 3.6, $\left.\mathrm{CI}_{95 \%}[1.7,7.6]\right)$ were more likely to suggest alternative outcomes, but pedestrians were not. Among participants who crossed before the train, the most common alternative described was that they would have stopped if the signals had been on for longer and/or if they had more time (i.e., they were farther from the crossing when the signals activated, or they were not in a hurry). Other potential deterrents to 
crossing before a train (all nominated by pedestrians) included if police/enforcement officers had been present, if it was not raining, or if they could see a train approaching.

Several drivers who stopped at the RLX indicated that they might cross before the train if they had been very close to the crossing when the signals activated or if it was an emergency and they needed to get somewhere quickly. Cyclists suggested they would cross if the signals were not active, if signals were active but the booms/gates had not yet closed, if signals appeared to be faulty, or if they were in a hurry. Pedestrian alternatives focused on ability to run across the tracks before the train arrived and sight distance; if they had a better view along the tracks and/or could not see a train, they would be more inclined to proceed. Motorcyclists were distinct from other road users in that they suggested not just situations in which they would cross before a train, but also alternative stopping behaviours (e.g., if they stopped for longer they might turn off the engine; depending on the traffic situation they would/would not filter through the queue). Situations that would prompt a motorcyclist to cross before a train were broadly similar to those mentioned by drivers and cyclists: if there was no train, if they were close to the tracks, if the boom gates had not yet descended, or if the signals appeared to be faulty. 